Portland State University

PDXScholar

\title{
A Comparison of Three Methods for Measuring the Attenuation Provided by Insert-Type Hearing- Protective Devices
}

Lois Jeanne Gaier

Portland State University

Follow this and additional works at: https://pdxscholar.library.pdx.edu/open_access_etds

Part of the Speech Pathology and Audiology Commons

Let us know how access to this document benefits you.

\section{Recommended Citation}

Gaier, Lois Jeanne, "A Comparison of Three Methods for Measuring the Attenuation Provided by InsertType Hearing-Protective Devices" (1988). Dissertations and Theses. Paper 3819.

https://doi.org/10.15760/etd.5703

This Thesis is brought to you for free and open access. It has been accepted for inclusion in Dissertations and Theses by an authorized administrator of PDXScholar. Please contact us if we can make this document more accessible: pdxscholar@pdx.edu. 
AN ABSTRACT OF THE THESIS OF Lois Jeanne Galer for the Master of science in speech Communication presented February 17, 1988.

Title: A Comparlson of Three Methods for Measuring the Attenuation Provided by Insert-Type HearingProtective Devices.

APPROVED BY MEMBERS OF THE THESIS COMMITTEE:

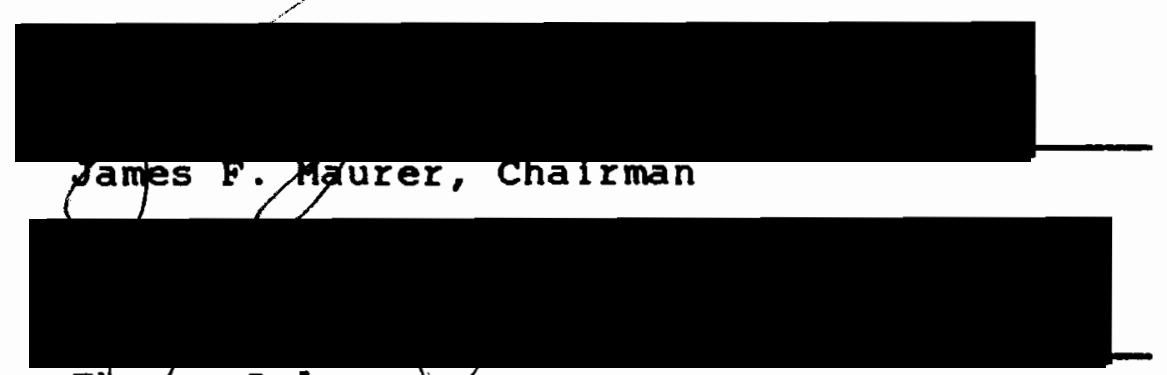

Thomas Dolan

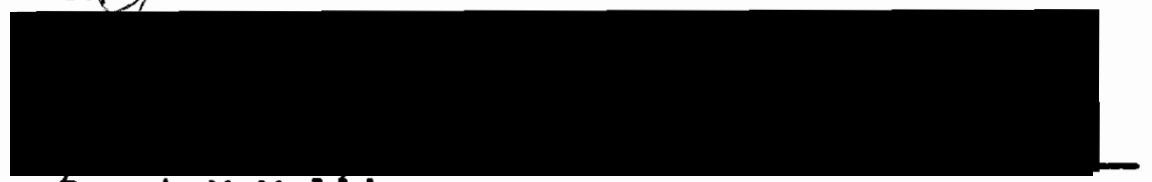

Brent McMuli in

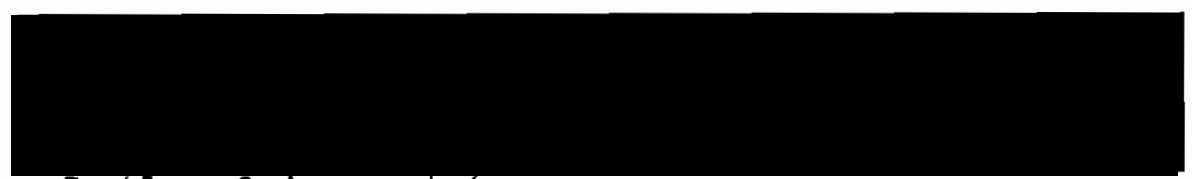

sandra oster

To effectively implement an occupational hearing conservation program, employers must know the amount of attenuation (noise reduction) provided by the hearingprotective devices used by their employees. Currently standardized test methods, performed under laboratory conditions, cannot be easily implemented in industrial 
settings, and previously proposed field methods have depended upon the use of special headphones which are not typically available in the workplace. These problems have led many occupational hearing conservationists to use standard audiometric headphones to evaluate the attenuation provided to employees using insert-type hearing-protective devices. There has, however, been little research into the validity of using standard audiometric headphones to determine attenuation values. The purpose of this study was to describe a procedure for determining the attenuation of insert-type hearing-protective devices using standard audiometric earphones, typical industrial audiometric equipment, and other easily obtainable materials.

Three different methods were used to evaluate the attenuation provided by an insert-type hearing-protective device, the E-A-R plug. The three methods used during this study were: (1) the use of one-third octave-band noise stimuli in sound-field, in accord with the current ANSI standard; (2) the use of pure-tone stimuli presented under an earphone/support combination; and (3) the use of puretone stimuli presented under earphones-only. Significant differences ( $p<.01$ ) were found between the sound-field and earphone/support methods at 3000 and $4000 \mathrm{~Hz}$. significant differences were found between the soundfield and earphonesonly methods at 2000 and $4000 \mathrm{~Hz}$. No significant differences in attenuation values were found between the three test methods at $1000 \mathrm{~Hz}$. 
The results of this study support the use, at selected Erequencies, of both the earphone/support method and the earphones-only method for measuring the attenuation provided by expandable foam insert-type hearing protectors such as those used in this study. The use of these methods with other types of insert-type hearing protective devices will require further evaluation before any rellable field tests can be conducted. 
A COMPARISON OF THREE METHODS FOR MEASURING THE ATTENUATION PROVIDED BY INSERT-TYPE HEAR I NG-PROTECTIVE DEVICES

by

LOIS JEANNE GAIER

A thesis submitted in partial fulfillment of the requirements for the degree of

\author{
MASTER OF SCIENCE \\ in \\ SPEECH COMMUNICATION \\ with emphasis in Audiology
}

Portland state University 
TO THE OFEICE OF GRADUATE STUDIES:

The members of the committee approve the thesis of Lois Jeanne Gaier presented February 17, 1988.

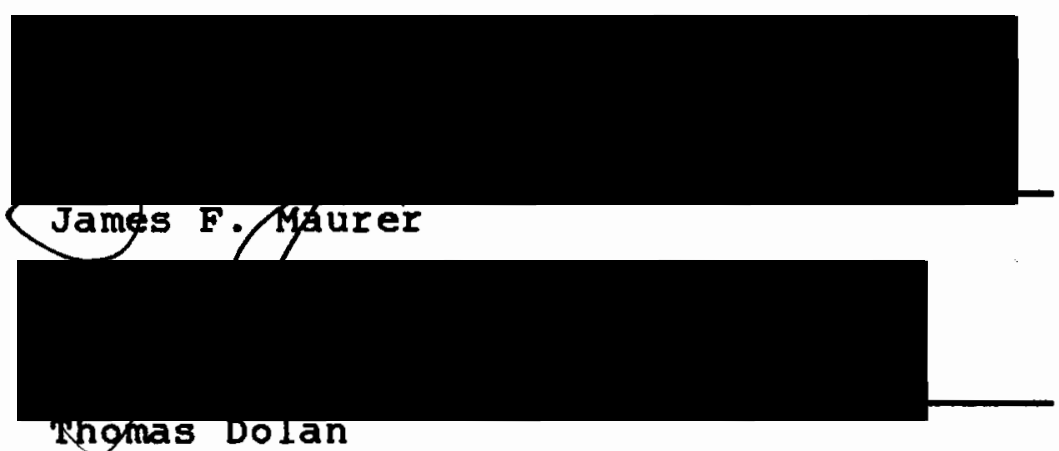

whinas Doran

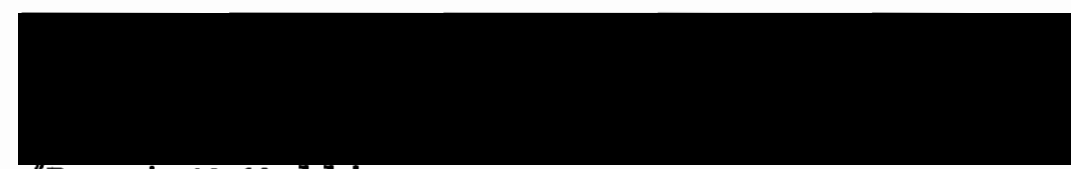

Brent McMuIIIn

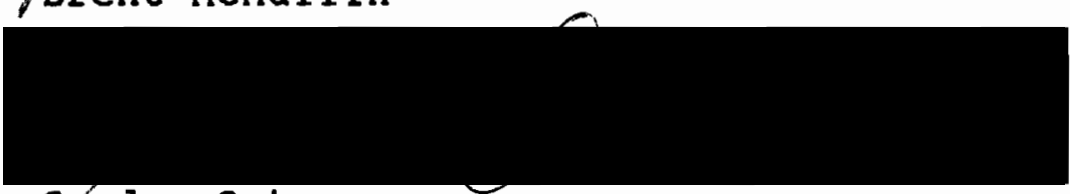

Sandra Oster

APPROVED :

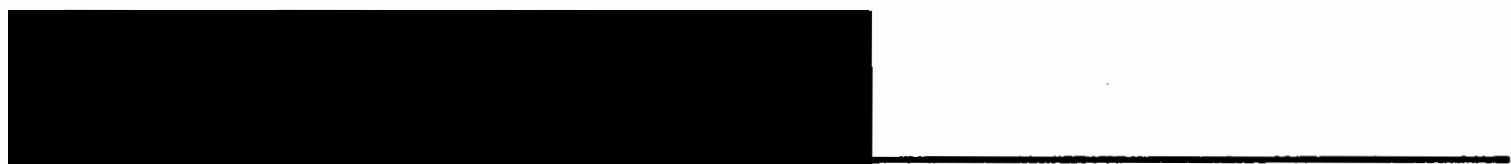

Mary Gordon\} Chalr, Department of Speech Communication

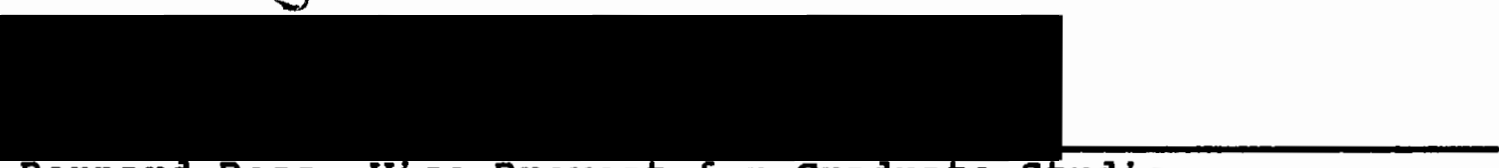

Bernard Ross, Vice provost for Graduate studies 
ACKNOWLEDGEMENTS

I wish to express my thanks and appreciation to all those who gave so willingly of their time and knowledge to assist me with the completion of this research.

First and foremost, I wish to thank my chairman and advisor, Dr. James F. Maurer, who supported me throughout all the "ups and downs" I encountered during this study. I wlll value, always, hls patlence, understanding, and support .

I wish to thank Brent McMulin, who shared his knowledge of hearing-protection and occupational hearing conservation so willingly with me, and who encouraged me throughout the course of this study.

Thank you, also, to Dr. Thomas Dolan for his invaluable advice and assistance during the course of this research study.

Very special thanks to Dr. James Paulson, without whose advice and assistance I could not have completed the proper statistical analysis of the data obtained in this study.

Special thanks, also, to Sandra oster for sharing her skills and knowledge of technical writing and for agreeing to serve on my thesis committee. 
TABLE OF CONTENTS

PAGE

ACKNOWLEDGEMENTS . . . . . . . . . . . . . . . . . iil

LIST OF TABLES . . . . . . . . . . . . . . . . . vi

LIST OF FIGURES . . . . . . . . . . . . . . . . VII

CHAPTER

I INTRODUCTION . . . . . . . . . . . . . 1

I I REVIEW OF THE LITERATURE. . . . . . . . . 6

Methods of Measuring HPD Attenuation . . 7

Subjective Methods

Objective Methods

Standards for the Measurement of

HPD Attenuation . . . . . . . . . . . . 9

History of Development of standards

The Current ANSI Standard

Why a Field Method for Measuring

Attenuation is Needed ........ 17

Laboratory Performance Versus Field Performance

Evaluating the Effectiveness of

Employee HPDs

II I METHOD . . . . . . . . . . . . . . 22

Subjects . . . . . . . . . . . . 22

Instrumentation . . . . . . . . . . 22

Procedure . . . . . . . . . . . 28 
IV RESULTS AND DISCUSSION • • • • • • • • • •

Results. . . . . . . . . . . . . . 32

Discussion . . . . . . . . . . . . . . 41

V SUMMARY AND IMPLICATIONS . . . . . . . . . . 54

summary • • • . . . . . . . . . . . 54

Implications . . . . . . . . . . . 55

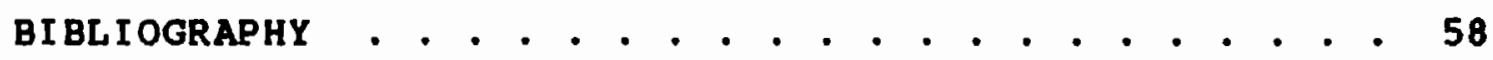

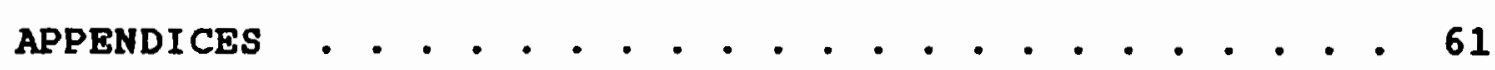




\section{LIST OF TABLES}

TABLE

P AGB

I Methods of Measuring Hearing Protector

Attenuation . . . . . . . . . . . 8

I Maximum Permissible Ambient Noise Levels

for Testing . . . . . . . . . . . . 12

II Summary of Data From pilot study conducted by

Berger Comparing Sound Field and Audiometer

Test Methods . . . . . . . . . . . . 15

IV Attenuation Values obtained Using

One-Third Octave-Band Noise Stimuli

in a sound-Field . . . . . . . . . . . . 34

v Attenuation Values obtained Using

Pure-Tone Signals Presented Under

Earphone/Support Combination . . . . . . . 35

VI Attenuation Values Obtained Using Pure-Tone

Signals Presented Under Earphones Only . . . 36

VII Attenuation Values - Means and standard

Deviations . . . . . . . . . . . . . 37

VIII Results of the Pillais Multivariate Test

of Significance . . . . . . . . . . . . 38

IX Results of Paired T-Tests Comparing Test

Methods . . . . . . . . . . . . . . 40

X Manufacturer and Field Attenuation Data

for the E-A-R Plug . . . . . . . . . . . . 
LIST OF FIGURES

F I GURE

PAGE

1. One-Third Octave-Band Nolse signal, $1000 \mathrm{~Hz}$ Center Frequency . . . . . . . . . 24

2. One-Third Octave-Band Noise signal, $2000 \mathrm{~Hz}$ Center Frequency . . . . . . . . 24

3. One-Third Octave-band Noise signal, $3000 \mathrm{~Hz}$ Center Frequency . . . . . . . . 25

4. One-Third Octave-Band Noise Signal, 4000 Hs Center Frequency . . . . . . . . 25

5. Block Diagram Illustrating Instrumentation

Used to Present the Nolse stimuli in

the Present study . . . . . . . . . . 26

6. The Circumaural "Earphone/support Combination" Designed for the present study . . . . . . 27

7. The InvestIgator Fit with the "Earphone/ support Combination" - . . . . . . . . 28

8. Means and standard Deviations for the Sound-Field Method and the Earphone/ support Method . . . . . . . . . . . . 43

9. Attenuation Values for Each Subject

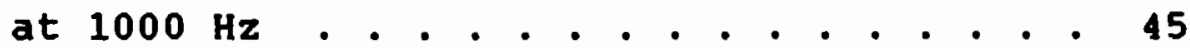

10. Attenuation Values for Each subject at $2000 \mathrm{~Hz}$. . . . . . . . . . . . . 46 
11. Attenuation Values for Each Subject

$$
\text { at } 3000 \mathrm{~Hz} \text {. . . . . . . . . . . . . } 47
$$

12. Attenuation Values for Each Subject

at $4000 \mathrm{~Hz}$. . . . . . . . . . . . 4 48

13. Means and standard Deviations for the

Sound-fleld Method and the Earphone/

Support Method . . . . . . . . . . 50

14. Means and Standard Deviations for all

Three Test Methods . . . . . . . . 50 
CHAPTER I

\section{NTRODUCTI ON}

The widespread use of personal hearing-protective devices in industry began following passage of the williamssteiger Occupational safety and Health Act in 1970 (Feldman, 1985). This Act and its subsequent amendments set minimum standards for industrial hearing conservation programs, including regulations governing employee noise exposure, noise control, and use of personal hearing-protective devices (Melnick, 1985). Employers are responsible for complying with these regulations and for assuring that their employees receive adequate hearing protection.

To effectively implement a hearing conservation program, employers must know the amount of attenuation (noise reduction) provided by the hearing-protective devices used by their employees. Manufacturers of hearingprotective devices are required to test their products to determine the amount of attenuation provided; most manufacturers report attenuation data obtained using standard test procedures outlined by the American National standards Institute (ANSI). Such tests are typically performed under laboratory conditions, requiring special instrumentation and facilities, trained listeners, and carefully fitted hearing-protective devices. These test 
conditions yleld optimum attenuation values, values which are not attainable under actual industrial conditions.

studies using ANSI procedures have also been conducted in typical industrial environments using actual employees as subjects and hearing-protective devices as normally worn by these employees. These studies have revealed significantly lower attenuation values for personal hearing-protective devices when compared to attenuation values obtained in laboratory tests (Padilla, 1976; Regan, 1975, 1977; Edwards, et al., 1978; Abel, et al., 1982; Edwards, et al., 1983; Riko \& Alberti, 1983). The differences between laboratory and "real-world" results, attributed to improper selection, fit, and use of hearing-protective devices in the field, demonstrate that the protection an employee actually obtains from his hearing-protective device is much less than the attenuation that these devices are capable of providing.

Formulas have been developed which adjust laboratory values to account for these differences, and these formulas are used by employers to estimate the protection afforded to employees under actual industrlal conditions. Such formulas, however, yield only estimates of protection, not the actual amount of protection afforded to individual employees. To obtain actual attenuation values requires that employees be tested according to standard test procedures while using their own hearing-protective devices. However, accepted ANSI procedures for determining attenuation values are difflcult to replicate under actual 
Industrial conditions. What is needed is a convenient, practical field method for measuring attenuation which will yield results as reliable as those obtained under laboratory conditions (Edwards et al, 1978).

There have been several studies which have attempted to define convenient and reliable field methods for measuring the effectiveness of hearing-protective devices (Regan, 1975, 1977; Michael, et al., 1976; Padi1la, 1976; Edwards, et al., 1978). These studies have yielded results which correlate well with results obtained using ANSI procedures. However, these studies employed specially designed headphones and equipment not available in typical industrial hearing conservation programs. There is little information in the literature concerning the feasibility or reliability of using standard audiometric headphones and equipment, although many occupational hearing conservationists currently use this method to measure the attenuation of insert-type hearing protectors for educational purposes (Berger, 1984; Berger, 1986).

A method of evaluating hearing-protective devices using standard industrial audiometric equipment would allow occupational hearing conservationists to better meet the needs of employees and to fulfill the requirements necessary for a successful hearing conservation program. Before such a method can be used with confidence, however, it must be shown to provide results as reliable as those obtained using the current ANSI standard test procedures. 
One of the purposes of this study is to evaluate a procedure for determining the attenuation of insert-type hearing-protective devices using standard audiometric headphones, typical industrial audiometric equipment, and other easily obtalnable materials. This procedure, conceived of as an alternate to the use of standard ANSI test methodology in the field, uses an earphone supporting device which fits around the ear and allows a standard audiometric earphone to be placed over the ear without altering the fit of the insert-type hearing-protective device being evaluated. This procedure is also an alternative to placing standard audiometric earphones directly on an employee's ears, a procedure which may possibly alter the fit of the hearing-protective device being tested.

The earphone supporting device used in this study can be easily constructed and, using the procedure described in this study, audiometric technicians in industry would be able to determine the attenuation of insert-type hearingprotective devices as they are actually worn by employees. Such information can be useful in administering and implementing an effective hearing conservation program in industry.

In this study, I will evaluate three different methods for measuring the attenuation provided by expandable foam insert-type hearing-protective devices. These methods include the standard ANSI test procedure, an alternate 
procedure using the earphone supporting device in confunction with standard audiometric earphones, and a second alternate procedure using standard audiometric earphones without the use of the supporting device. I will attempt to determine if the alternate procedures produce results that differ significantly from results obtained with the standard ANSI test methodology.

The questions to be answered in this study include: (1) Can a practical, reliable method for measuring the attenuation of insert-type hearing protectors be devised using standard industrial audiometric equipment; and (2) Do the results obtained using such a method correlate with results obtained using standard ANSI procedures? 
CHAPTER TWO

REVIEW OF THE LITERATURE

The Department of Labor's Occupational Noise ExposureHearing Conservation Amendment, effective 8-21-81, requires that employers make hearing-protectlve devices (HPDs) avallable to employees exposed to noise levels of 85 dBA or greater based on an 8 -hour time-weighted average (TWA/8hr). The TWA is a measure of the amount of nolse to which an employee is exposed during his workday: HPD use is mandatory at noise levels of $90 \mathrm{dBA}$ ( $\mathrm{TWA} / 8 \mathrm{hr}$ ). Employers are also required to evaluate the attenuation provided by HPDs for the specific nolse environments in which the HPDs will be used in order to ensure that employee noise exposure is reduced to $90 \mathrm{dBA}$ (TWA/8hr) or below.

The noise reduction provided by an HPD is popularly referred to as its attenuation, but attenuation is not a precisely defined acoustical term. Berger (1986) points out that it is more accurate to use insertion loss when discussing the attenuation provided by hearing-protective devices. Insertion loss is the difference between the sound pressure levels, sound power levels, or sound intensity levels, measured at a reference point before and after a particular noise reducing treatment is applied. Insertion loss provides a measure of the reduction in sound level at 
the eardrum which occurs when an HPD is fitted to the ear (Martin, 1982). Insertion loss provides the most accurate assessment of attenuation according to Berger (1986). In the present study, attenuation refers to the insertion loss value of the HPD.

The correct measurement of attenuation has been the subject of much research during the past 50 years. Numerous measurement methods have been proposed and tested, but none has been universally accepted (Berger, 1986). In this review of the literature, I will first discuss the methods available for measuring the attenuation provided by HPDs. I will then discuss the development of standards for the measurement of attenuation and the requirements for the current ANSI standard. Finally, I will discuss why a field method for measuring the attenuation of HPDs is needed.

METHODS OF MEASURING THE ATTENUATION OF HPDS

Current laboratory methods for measuring the effectiveness of HPDs can be divided into two major categories: subjective and objective. These two methods complement one another; both types of measurements are useful to fully define the performance of HPDs (Berger, 1986). Berger (1986) provides a comprehensive review of the subjective and objective methods currently in use; Table I, from Berger, outlines these methods. 
TABLE I

METHODS OF MEASURING HEARING PROTECTOR ATTENUATION

I. Subjective methods

A. Real-ear attenuation at threshold (REAT)

1. Sound field REAT

2. Headphone REAT

3. REAT with hearing-impaired subjects

B. Above-threshold procedures

1. Masking

a. Earphone stimuli

b. Bone-conduction stimuli

2. Loudness balance

3. Midline lateralization

4. Temporary threshold shift

5. Speech intelligibility

6. Miscellaneous psychophysical methods a. Cross modality loudness scaling

b. Magnitude estimation

c. Reaction time

II. Objective methods
A. Acoustical test fixture (artificial head/ear)
B. Microphone in real ear
C. Microphone in cadaver ear
D. Aural-reflex threshold shift

Subjective Methods

Subjective methods rely upon a subject's response to a stimulus under two separate conditions: when wearing hearing protection (occluded threshold) and when not wearing hearing protection (open threshold). The difference between these two response measures equals the insertion loss of the HPD.

Subfective test methods include both real-ear attenuation at threshold (REAT) methods and above-threshold methods. The REAT methods are the most commonly used in measurement standards, both in the United States and abroad 
(Humes, 1983 ).

objective methods rely on instrument readings instead of subject responses; the difference between instrument readings in the occluded threshold and open threshold conditions equals the insertion loss or noise reduction value of the HPD (Berger, 1984).

Objective methods include: (1) acoustical test fixture; (2) microphone in real ear; (3) microphone in cadaver ear; and (4) aural-reflex threshold shift.

STANDARDS FOR THE MEASUREMENT OF HPD ATTENUATION

Because they provide a set of firm, clearcut guidelines for accomplishing a specific task, standards allow results obtained by one test facility to be compared to results obtained by other facilities (Nixon, 1982). Standards for the measurement of HPD attenuation specify procedures, instrumentation, and methods to be used; all requirements are exactly defined so as to be uniform and easily repeatable.

History of Development of Standards

Prior to World War II, there were few test facilities active in testing HPDs. Work was confined to a few independent laboratories and there was little need for intercommunication or interchange of ldeas or results.

Following World War II, the growing use of fet engines in military and commercial aircraft generated increased 
interest in the study of HPDs. The number of HPDs available at the time was limited; consequently, the few test facilities active often measured the effectiveness of the same HPDs. When these facilities began comparing results, they found wide variations in performance of the HPDs, as each laboratory was using significantly different measurement procedures than the others (N1xon, 1982).

The differences in attenuation values obtained by these varlous researchers, most of whom were members of the Acoustical society of America, led them to promote the need for standardized measurement procedures. The subsequent result was the American National standards Institute (ANSI) "standard for the Measurement of the Real-Ear Attenuation at Threshold, ANSI $224.22,1957 . "$ The use of this standard increased as hearing conservation practices were adopted more widely by industry and by the military (Nixon, 1982). The 224.22 standard was later revised in 1974 and aga in in 1984. The current standard is ANSI S12.6-1984, "Method for the Measurement of the Real-Ear Attenuation of Hearing Protectors (ANSI, 1984)."

standards allow us to determine the optimum performance of HPDs, which then is our "benchmark" for performance (Berger, 1982). The current standard, which uses a real-ear at threshold (REAT) test procedure, simulates, as realistically as possible, the types of sounds which typically occur in the industrial environment while still maintaining experimental accuracy and reproducibility. The 
REAT procedure described in the standards is used by almost all manufacturers of HPDs when determining the attenuation values of their products.

The sound-field real-ear attenuation at threshold method, the oldest and most common method of measuring HPD attenuation, is the method specified in the current standard, ANSI 12.6-1984. It is also the method preferred for field testing of HPDs (Hume, 1983; Berger, 1986). The REAT method takes into account all sound paths to the inner ear (Berger, 1984; Berger, 1986). Using an absolute threshold shift technique, a subject's binaural threshold is first determined without hearing protection (open threshold) and is then remeasured while the subject is wearing hearing protection (occluded threshold). The difference between the open and the occluded thresholds is a measure of the insertion loss provided by the HPD (Berger, 1986).

\section{The current ansI standard}

The current ANSI standard, s-12.6-1984, "Method for the Measurement of the Real-Ear Attenuation of Hearing Protectors," may be found in Appendix A. In this section, I will discuss the requirements for conducting accurate REAT tests, as defined by the current standard, and the feasibility of following these requirements under typical industrial conditions, keeping in mind that the instrumentation avallable in industry is usually a limited range air-conduction audiometer with pure-tone stimuli used 
with standard headphones and a small sound-treated booth.

Ambient noise. A basic requirement of accurate REAT measurements is that the test room be free of excessive ambient nolse, since significant ambient noise levels tend to mask, and hence elevate, the open ear thresholds while leaving the occluded thresholds relatively unaffected (Berger, 1986). ANSI 12.6-1984 specifles maximum permissible ambient noise levels in SPL for the octave bands from 125 through $8000 \mathrm{~Hz}$. These levels are much more stringent than those required by the occupational safety and Health Administration (OSHA) for audiometric testing in industry. In Table II, the permissable levels for the ANSI standard and for OSHA testing are listed. To meet the levels required in the ANSI standard, special acoustical test spaces are required; such low noise levels are extremely difficult to meet under typical industrial conditions.

TABLE I I

MAXIMUM PERMISSIBLE AMBIENT NOISE LEVELS FOR TESTING Frequency, $\mathrm{Hz}$ Octave band, SPL*

125

250

500

1000

2000

4000

8000
ANS I $512.6-1984$

$$
\begin{array}{r}
28 \\
18 \\
14 \\
14 \\
8 \\
9
\end{array}
$$

20
OSHA

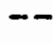

40

40

47

57

62

*Permissible ambient nolse levels are in decibels re 20 upa 
One way of circumventing the problem of excessive ambient noise levels is to use a REAT under headphones method. The use of headphones lessens the need for a quiet acoustical space and eliminates the need for a special test room (Berger, 1986). The attenuation provided by the headphones makes the test results less sensitive to ambient noise in both the open and occluded ear test conditions (Berger, 1986). The limitations of this method are that it is not covered in the current standard and it is useful only for testing insert-type HPDs. This method has, however, been used in several studies which have evaluated the attenuation provided by HPD's in the field, and it has been found to provide valid, reliable attenuation results.

The headphone REAT procedure was first implemented by Padilla (1976), who used a modified set of large circumaural earmuffs with TDH-39 earphones attached. It was most fully developed, however, by Michael, et al. (1976) under contract to the National Institute for Occupational Safety and Health (NIOSH). Using special headphones developed by the Environmental Acoustics Laboratory (EAL) at Pennsylvania state University, Michael, et al. (1976) found that the correlation between the EAL headphone method and the standard method, ANSI 33.19-1974, was "sufficient to establish the validity of a human subjects test using the headphones ( $p, 3)$." The headsets constructed for this study consisted of Beyer DT-48S earphones and earcups from the American Optical Model 1200 earmuff type hearing protector. 
These headphones provided a relatively smooth frequency response; high, undistorted sound-output level; good isolation from external nolse; and large earcups which did not disturb the natural position of the pinna and which allowed space for protruding earplug tabs.

Edwards, et al. (1979) conducted tests according to ANSI 224.22-1957 methodology, and using the same subjects, conducted tests using the specially designed EAL headphones following ANSI s3.19-1974 methodology. This study revealed no statistically significant differences between the results of the two test procedures, thus demonstrating the reliablity of headphone versus sound-field test results.

The ability to use standard rather than speclally designed audiometric headphones would be useful for audiometric technicians who wish to measure the attenuation of HPDs on individual employees in the workplace. Only one author (Berger 1984) has reported data regarding the validity of such a test method. Four different types of earplugs were evaluated in sound-field according to ANSI s3.19-1974 procedures; these same earplugs were then evaluated using a REAT procedure and headphones consisting of TDH-50 earphones mounted in MX 41-AR cushions. All testing was conducted monauraliy with the non-test ear occluded by an E-A-R earplug covered by a David Clark 10A earmuff. In general, the results of the sound-field and standard headphone REAT methods were not significantly different, although for certain earplug/ear canal 
combinations the headphone test yielded large overestimations ( $>10 \mathrm{~dB}$ ) of the sound-field attenuation (see Table III).

\section{TABLE III}

SUMMARY OF DATA FROM PILOT STUDY CONDUCTED BY BERGER COMPARING SOUND-FIELD AND STANDARD HEADPHONE METHODS

Data is summarized in terms of means and standard deviations for each frequency and each method. standard deviations are listed in parentheses following the mean value.

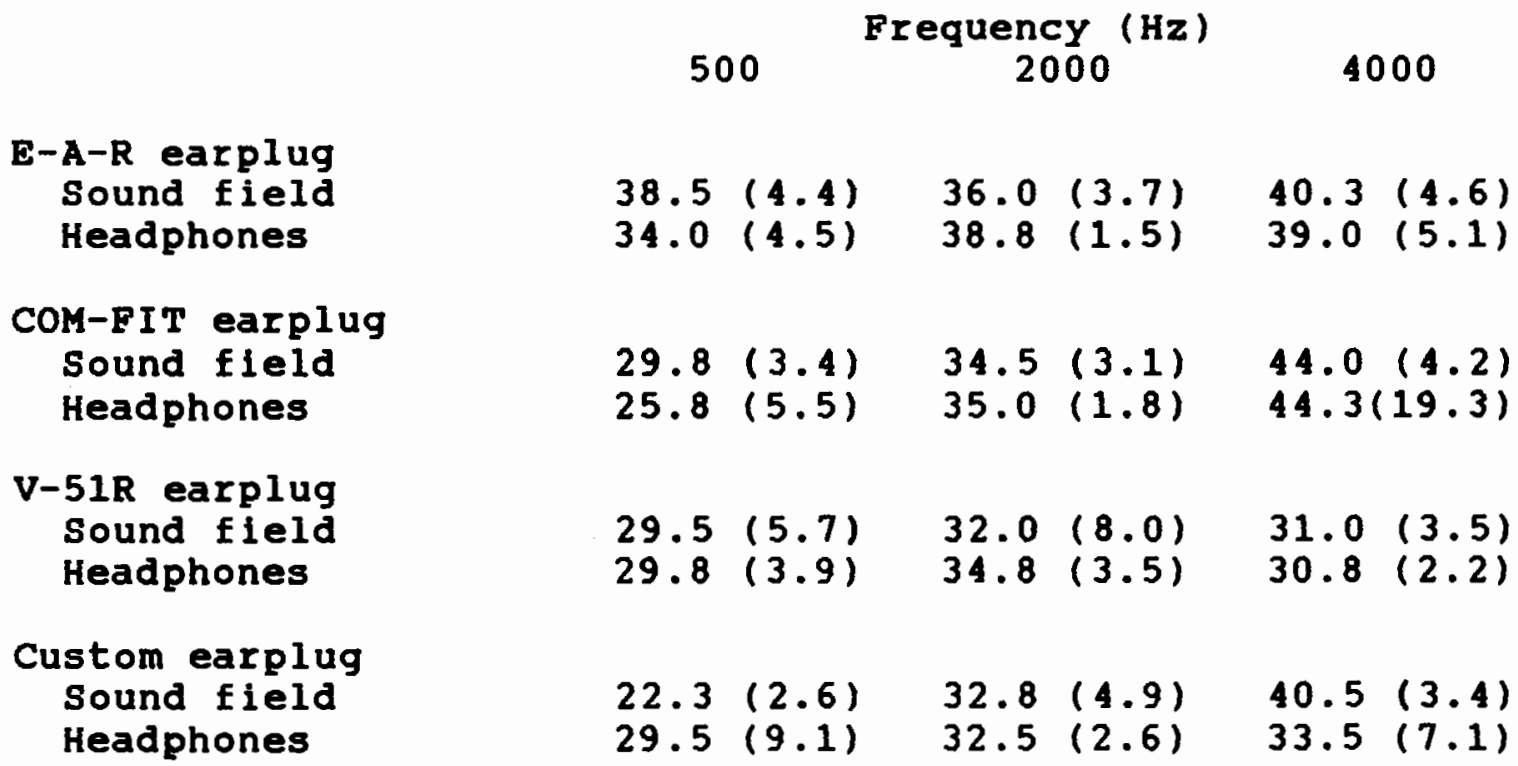

In discussing the use of standard audiometric headphones for evaluating the attenuation provided by insert-type hearing protectors, Berger listed the following objections :

The reliability of this approach is questionable because: (a) the earphone may actually rest on the protector causing it to either break its seal or to be pushed farther into the canal, depending upon the design of the HPD and the particular fit being tested; (b) resting an earphone on the pinna can distort the concha and/or canal, changing the fit of the insert; (c) possible plug/earphone contact can create structural instead of acoustical 
excitation of the insert; and (d) the acoustical excitation of the plug inside the small occluded volume under the supra-aural device is not representative of sound-field excitation and may actually change as the occluded volume is reduced by the application of the HPD (p. 1665).

Before a reliable field method can be formulated using standard audiometric earphones and equipment that is readily avallable in industry, a way of avolding the problems stated by Berger must be overcome.

stimulus bandwidth and directivity. The earliest ANSI standard, 224.22-1957, specifled the use of pure tone stimuli at octave-band center frequencies presented in an anechoic chamber at frontal incidence. The results obtained were regarded as measures of the octave-band attenuation for the HPD tested. Later American standards specified the use of one-third octave-band stimuli presented in a reverberent room. These changes were made because sound-field one-third octave-band stimuli were felt to be more representative of actual industrial nolse conditions (Berger, 1979; Nixon, 1982).

Several studies have compared sound-field REAT results obtained using pure-tone stimuli with those obtained using noise band stimuli. Webster, et al., (1956), compared REAT results for pure-tone, $1 / 2$ octave-band noise, and octaveband noise stimuli, with the center frequency of the nolse bands corresponding to the pure-tone frequencies tested. Applying critical band corrections when computing attenuation for the nolse band data, they concluded that the 
use of bands of nolse or the use of pure-tones yielded results that were essentially the same except around 4000 $\mathrm{Hz}$, where pure-tone attenuation was higher.

Waugh (1974) also compared REAT results using pure-tone and one-third octave-band stimuli. Waugh concluded "that puretone and one-third octave-band measurements may be regarded as identical for all practical purposes (p. 1867)."

other studles have compared results using ANSI 224.22 1957 procedures, using pure-tone stimul1, with results obtained using standard procedures specifying one-third octave-band stimull. Berger (1986) reported that attenuation values obtained for earplugs were essentially the same in these different tests.

Edwards, et al. (1979) conducted testing using puretone stimuli presented in an anecholc chamber (ANSI 224.221957 procedures) and, using the same subjects, conducted tests using one-third octave-band noise stimuli delivered through the specially designed EAL headphones in accord with ANSI s3.19-1974 methodology. These researchers found no statistically significant differences between the results of the two test procedures.

WHY A FIELD METHOD FOR MEASURING ATTENUATION IS NEEDED

The data obtained using standard ANSI test procedures represent the optimum attenuation values of which an HPD is capable. The current standard (ANSI S12.6-1984) states that, under fleld conditions, these laboratory values will 
"depict the noise-reducing capabilities of hearing protectors only to the extent that users wear the devices in the same manner as did the test subjects (p.1)." The fitting procedures employed in the standards are intended to simulate how an educated and reasonable worker should fit his protectors in the workplace (Martin, 1982). The actual estimation of attenuation provided to a real worker, however, depends upon many factors of HPD usage which are beyond the control and scope of the ANSI standard. These factors include the level of employee education and motivation amd the comfort of the HPD (Berger, 1982).

\section{Laboratory Performance Versus Field Performance}

Even with the best possible industrial fitting, training, and motivational programs, the performance of HPDs in the field do not approach the high values obtained with exacting laboratory fittings (Berger, 1982). standardized laboratory data on HPD performance have been available since the 1950s (ANSI Z24.22-1957), and, since the mid 1970s, there has been significant research into the fleld performance of HPDs (Berger, 1984). Varlous studies have demonstrated the disparity between results obtalned in the laboratory and those obtained in the field (Padilla, 1976; Regan, 1975, 1977; Edwards, et al., 1978; Abel, et al., 1982; Edwards, et al., 1983; Riko \& Albert1, 1983). Regan (1975, 1977) collected attenuation data by taking subjects directly from their work station to a nearby 
audiometric van and performing tests using the ANSI 224.221957 methodology. His results indicated that manufacturers' attenuation data do not accurately reflect the amount of protection actually provided to the worker while on the job.

Padilla (1976) used a modified set of circumaural earmuffs with TDH-39 earphones suspended inside the earmuffs so that standard audiometry equipment could be used to obtain attenuation data. His data, compared and correlated with ANSI 53.19-1974 procedures, indicated that "laboratory tested standard ear plug data do not represent the actual field conditions studied. Consequently, the effectiveness of the device under field usage may be grossly overestimated (p. 36)."

Edwards, et al., (1978, 1983) using a fleld method and speclal headphones developed by Michael, et al., of the Environmental Acoustics Laboratory (EAL) at Pennsylvania state University, tested workers in a mobile audiometric van. Workers were taken directly from the workplace and tested without their prior knowledge of the test time and without being allowed to adjust their hearing protectors. Results of this study supported the conclusion "that the average industrial worker does not receive the protection from his or her earplugs that is established for the protectors under laboratory testing conditions (p.14, $1983)$."

Abel, Alberti, \& Riko (1982) and Riko \& Alberti (1983), using standard REAT procedures, tested workers wearing their 
own hearing protectors under laboratory conditions. Results indicated that the attenuation afforded to workers varied widely, and the authors identified three major problems contributing to the differences between laboratory performance and field performance: inappropriate fitting, poor maintenance, and deliberate abuse of devices.

\section{Evaluating the Effectiveness of Emoloyee HPDs}

Because of the differences between laboratory and field attenuation values, there has been an increasing desire to measure attenuation obtained among users of HPDs in the "real world" of actual work environments (Gasaway, 1985). It is important to document the actual effectiveness of HPDs as they are used in the workplace, and it is also very important that a convenient, reliable, easily implemented procedure be available for use.

Besides providing employer compliance with OSHA regulations, testing employees with their own HPDs can serve as a valuable educational and motivational tool in the hearing conservation program. Harvey (1981) reported that employees tested while using their own HPDs learned to obtain significantly greater attenuation with their HPDs. Real-world assessments could be used to, as Gasaway (1985) states :

... enhance education and indoctrination sessions, to assess actual amounts of attenuation being obtained by an individual who exhibits a possible noise-induced hearing loss, and to select and fit better specific types of hearing protectors.... Realworld assessments will also be of interest to others: 
Insurers, lawyers, inspectors, enforcers, and others who desire to credit or discredit the effectiveness of hearing protectors for any reason (pp. 154-155)."

As interest in assessing attenuation in the industrial setting grows, new test procedures will need to be developed which can be easily implemented using equipment avallable in current hearing conservation programs. A practical field method is needed because of the impracticality of duplicating the ANSI methodology in the field, even in a mobile facility (Edwards, et. al., 1978). A fleld test method must be portable and usable with untrained subjects; equipment must be set up at the location where the HPDs are used; and a psychophysical method of testing famlliar to the employee must be used (Berger, 1984).

If a method can be devised which, under laboratory conditions, can be shown to provide data which does not differ signiflcantly from data obtained using standard ANSI procedures, it can be used with confidence in the field to assess the attenuation provided by an employee's personal HPD. Such a method would make use of the equipment avallable in most industrial hearing conservation programs: a 11 mited range, air-conduction audiometer, standard audiometric earphones, and pure-tone stimuli presented in an acoustically controlled environment. 
CHAPTER THREE

METHOD

SUBJECTS

Ten normal hearing subjects were used. All subjects had hearing threshold levels within the range of $-10 \mathrm{~dB}$ HL to $20 \mathrm{~dB} \mathrm{HL}$ at test frequencies of $250,500,1000,2000$, $3000,4000,6000$, and $8000 \mathrm{~Hz}$. These levels met the criterion for pure-tone thresholds outlined in the American National standard for the Measurement of the Real-Ear Attenuation of Hearing Protectors, ANSI S12.6-1984 (see Appendix A). Subjects, 9 Eemale and 1 male, ranged from 18 to 37 years of age and were experienced at taking pure-tone alr-conduction audiometric tests.

\section{INSTRUMBNTATION}

The study was conducted in an acoustically treated test room (International Acoustics Corporation, Model 1403) located at Portland state University. This room meets the requirements for maximum permissable ambient noise levels specified in ANSI s12.6-1984. All physical requirements as specifled in the current standard were met regarding test sounds, sound-field characteristics, test apparatus, signal source, control circuits, loudspeakers, head-positioning 
device, and distortion (see Appendix A).

A calibrated Maico audiometer (Model 24B) was used to generate the sound stimuli and to control the level of the stimuli presented to the subject. Pure-tone test signals were delivered through TDH-39 earphones with MX-41/AR cushions. Nolse stimuli were delivered to the subject in sound-field using two Electrovolce, model century, louds peakers.

The pure-tone and noise stimuli were generated and attenuated by means of a callbrated audiometer (Malco 24B). For pure-tone stimuli, the output of the audiometer was routed to a TDH-39 earphone mounted in an MX-41/AR cushion. For noise stimuli, a white noise signal generated by the left channel of the audiometer was routed through a Bruel and KJaer, series 1616, one-third octave-band pass filter. The narrow-band was then routed through the right channel of the audiometer, amplifled (Mckintosh, model 50), and delivered to the two loudspeakers (Electrovolce, model Century) in the test room. The one-third octave-band nolse signals generated by this system were analyzed at the speaker input by using a Nicolet 444-A spectrum Analyzer; these signals are lllustrated in Figures 1 through 4. A block diagram of the instrumentation for the noise stimuli is lllustrated in Figure 5 . 


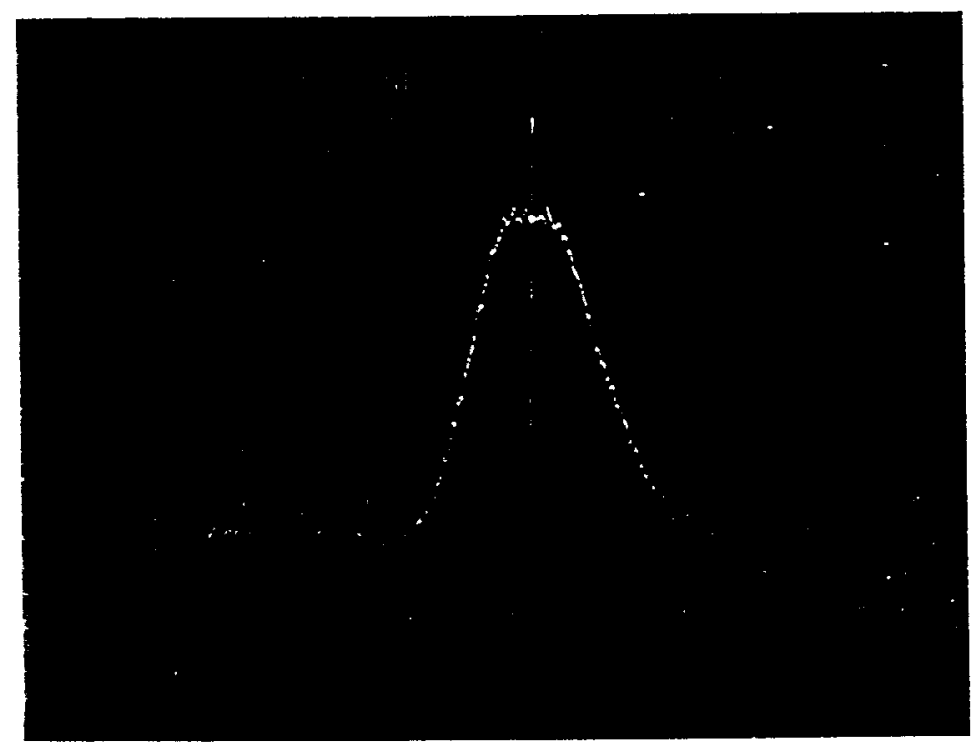

Fiqure 1. One-third octave band noise signal, $1000 \mathrm{~Hz}$ center frequency.

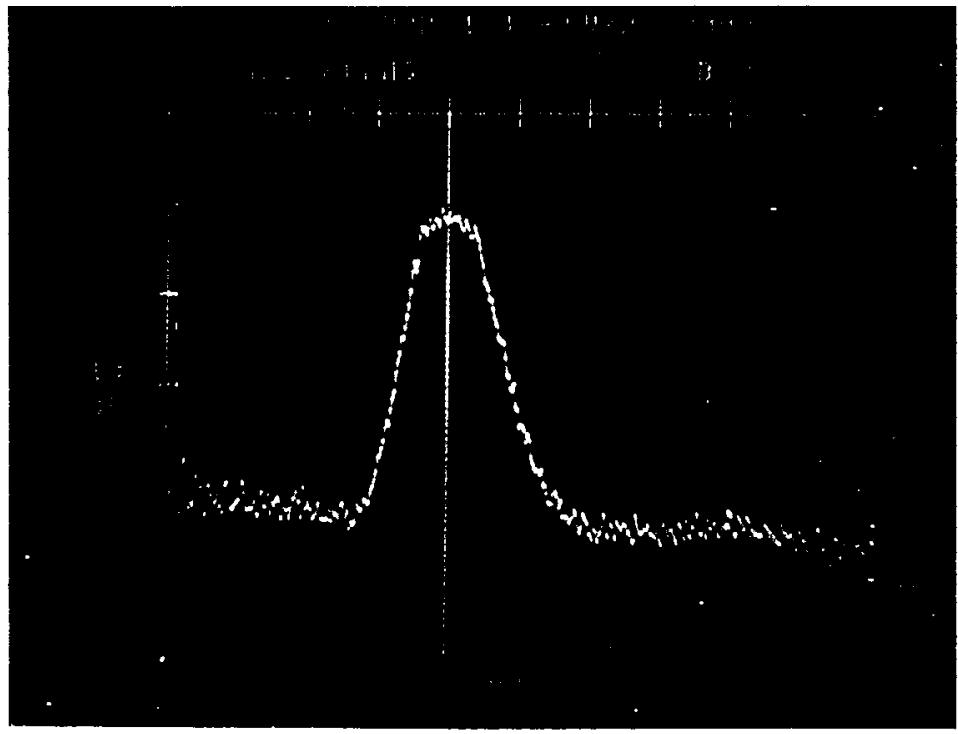

Fiqure 2. One-third octave-band noise signal, $2000 \mathrm{~Hz}$ center frequency. 


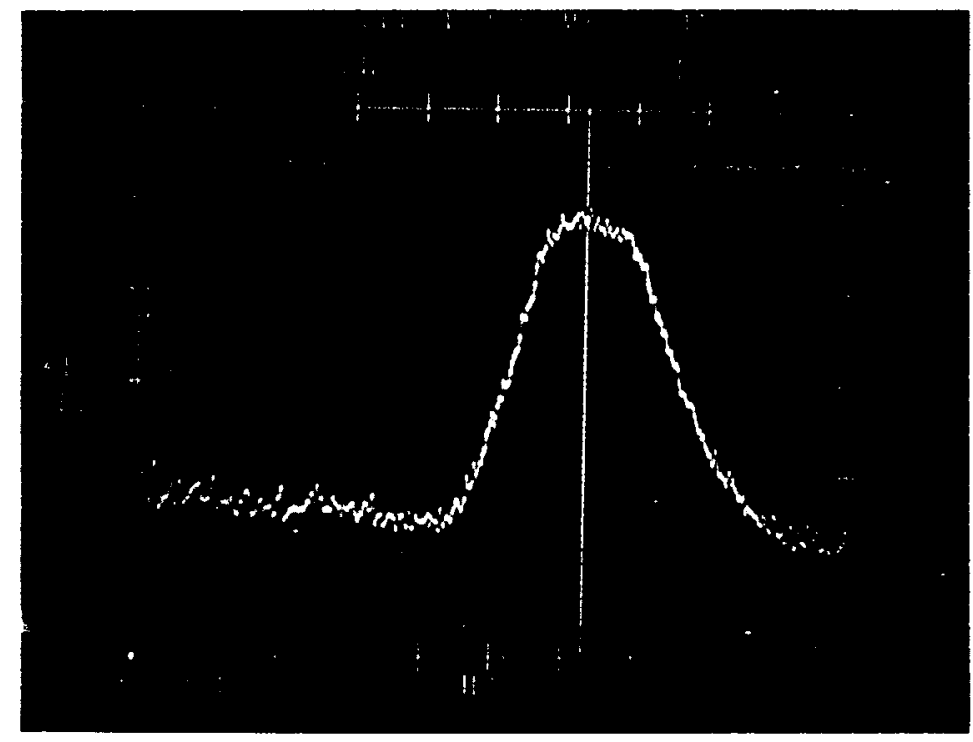

Elqure 3. One-third octave-band nolse signal, $3150 \mathrm{~Hz}$ center Erequency.

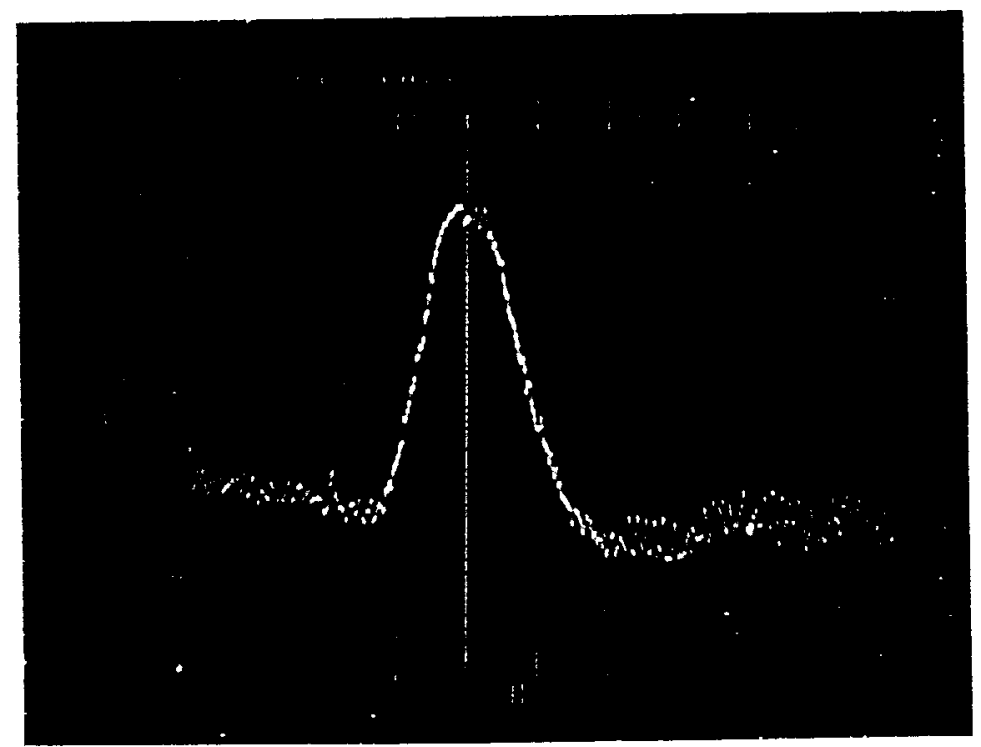

Fiqure 4. One-third octave-band noise signal, $4000 \mathrm{~Hz}$ center Erequency. 

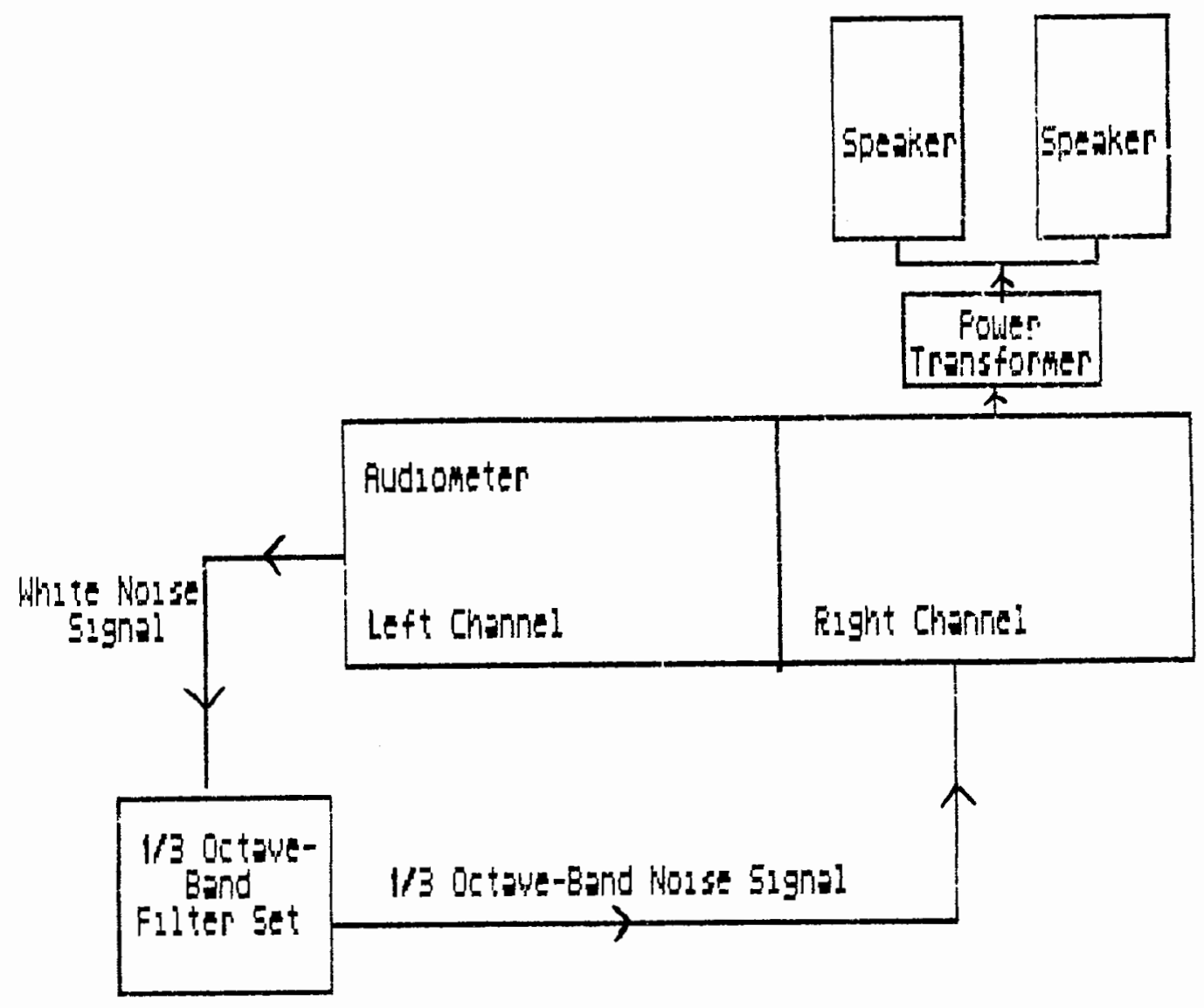

Elqure 5 . Block diagram illustrating instrumentation used to present the noise stimuli in the present study.

A circumaural supporting device was used in confunction with the standard audlometric earphones for one of the test methods evaluated in this study. This device was designed to encircle the ear in order to support the standard audiometric earphone cushion and to prevent the earphone from resting directly on the pinna and distorting the flt of the earplug during testing. This "support" was constructed from polymer foam having a density of $1.5 \mathrm{lbs} / \mathrm{cubic}$ foot, and plastic. A plece of foam, (4" long, 4" wide, 1" thick) was attached to a $4^{\prime \prime}$ diameter, flat plastic disc using a commercially avallable clear silicon sealer. Before sealing 
the foam to the plastic, an oval opening 3 " high and 2" wide was cut in the center of the foam piece to accomodate the pinna, and a 1" diameter hole was cut in the center of the plastic disc to accomodate the diaphragm opening of the earphone. In the present study, this device used in conjunction with the standard audiometric earphone is referred to as the "earphone/support combination" and is illustrated in Figures 6 and 7 .

The earplug used in this study was the E-A-R plug, a disposable, wearer-molded plug made of a polymer foam. This cylindrically-shaped plug is designed to be compressed and inserted into the ear canal, where it expands to fit the contours of the ear canal. This device has been extensively

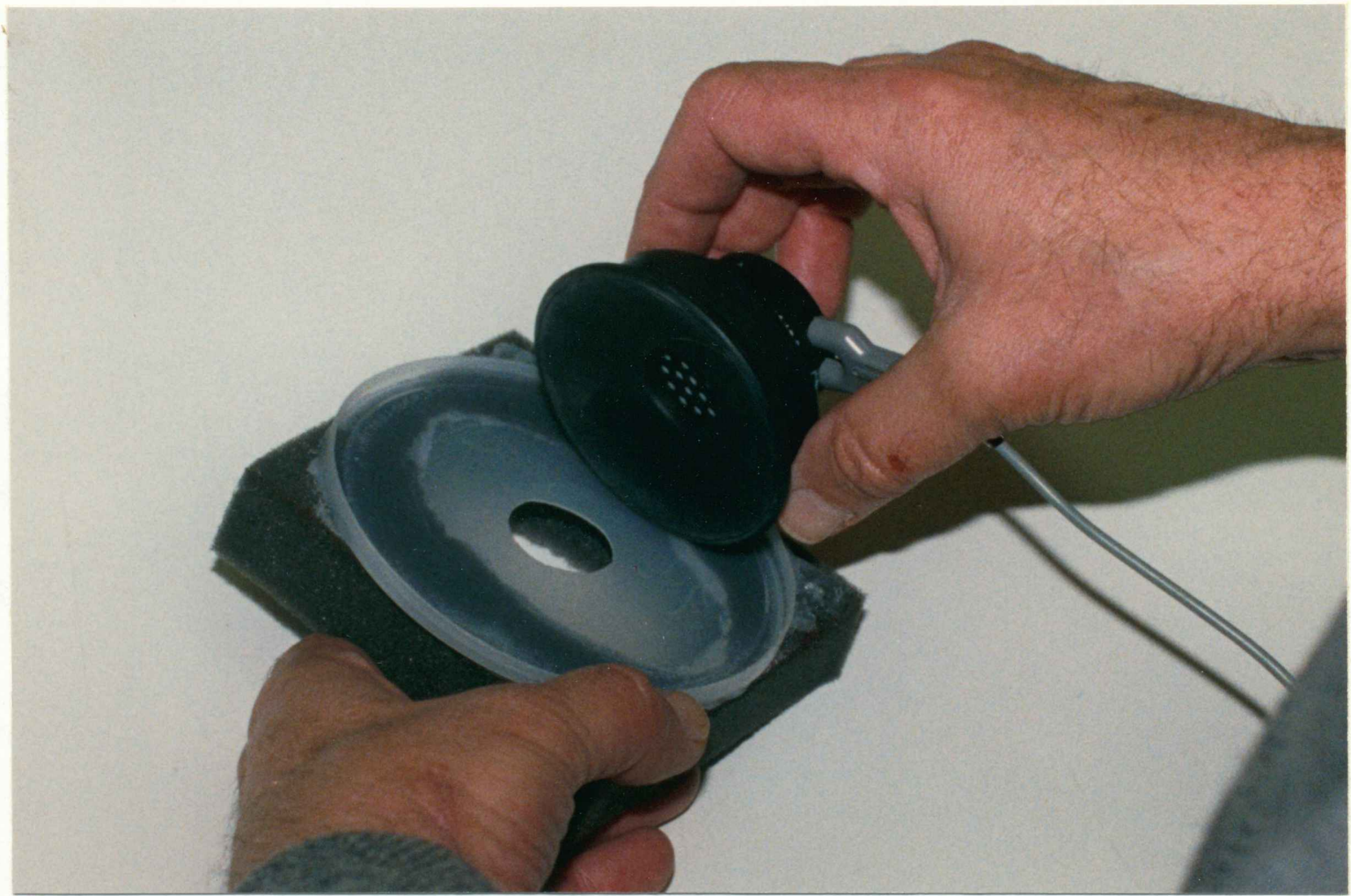

Eiqure 6. The circumaural "earphone/support combination" designed for the present study. 


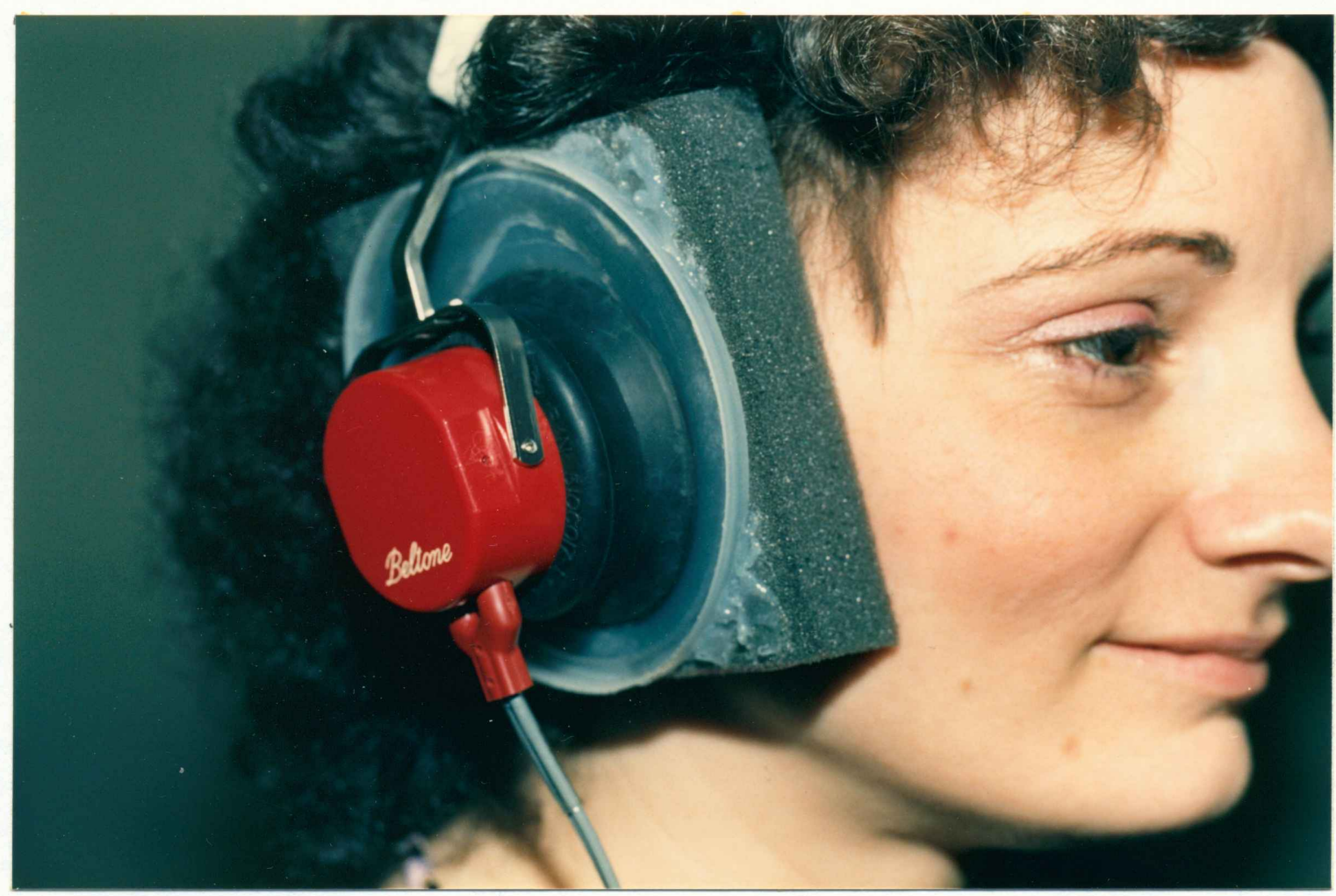

Elqure 7. The investigator fit with the "earphone/ support combination."

studied under laboratory conditions and is one of the most commonly used insert-type hearing-protective devices in occupational hearing conservation programs.

\section{PROCEDURE}

One insert-type hearing protective device, the $E-A-R$ earplug, was evaluated during this study. The attenuation provided by this earplug was determined by obtaining open and occluded real-ear-at-threshold measurements under three different test conditions: (1) using one-third octave-band stimuli in a sound-field; (2) using pure-tone stimuli presented under the earphone/support combination; and 
(3) using pure-tone stimuli presented under earphones only. All testing was conducted monaurally by occluding the nontest (left) ear with a fully inserted E-A-R plug covered by a Flents "silenta" earmuff (model 0800).

The one-third octave-band nolse stimuli were presented at center frequencies of $1000,2000,3150$, and $4000 \mathrm{~Hz}$, and the pure-tone stimuli at frequencles of 1000, 2000, 3000, and $4000 \mathrm{~Hz}$. Hearing threshold levels were determined to the nearest decibel step on the audiometer attenuator using a method-of-limits psychophysical test procedure, a modifled Hughson-Westlake procedure, as described by Carhart and Jerger (1959), but using a "up 1 dB-down 2 dB" approach for establishing threshold.

Each subject was given a practice test at the beginning of the test session, with pure-tone alr-conduction threholds obtained using standard audiometric earphones. Following the practice test, the subject was shown how to insert the E-A-R plug, using instructions provided by the manufacturer (see Appendix $B$ ). The plug was inserted into the non-test ear and that ear was then covered with the silenta earmuff. An open sound-field threshold for the test ear was then determined using one-third octave-band noise stimuli. The subject was then instructed to insert an E-A-R plug into the test ear. During insertion of the plug, white noise at a level of $70 \mathrm{~dB}$ SPL was introduced into the test chamber and the subject was allowed to manipulate the plug until satisfled that the nolse was reduced to a minimum. The fit 
of the earplug was then visually checked by the investigator. Occluded thresholds were then determined using the narrow-band noise stimuli.

After obtaining open and occluded thresholds in soundfield, the subject was prepared for testing with the earphone supporting device. The silenta earmuff was removed from the non-test ear and the earphone supporting device was placed over the test ear; both ears were then covered by the standard audiometer earphones with the earphone cushion on the test ear resting on the plastic disc of the earphone supporting device and the diaphragm of the earphone centered over the opening in the plastic disc. Occluded thresholds were then obtained. The earphone supporting device was then removed and occluded thresholds for the earphones-only condition were obtained. The E-A-R plug was then removed from the test ear and open thresholds were obtained, first for the earphone/support condition and then for the earphones-only condition.

The above procedure was repeated two more $t$ imes with each subject; the test sequence remained the same for each of the three trials for all subjects. The earphone tests were always conducted after the sound-field tests so that any alteration of the fit of the plug caused by the earphone would not affect the sound-field test results.

For each Erequency and each test method, the threshold level in the unoccluded condition was subtracted from the threshold level in the occluded condition to obtain the 
attenuation value of the E-A-R plug. Mean attenuation values across subjects and trials were obtained for each test method and each frequency combination. 


\section{CHAPTER IV \\ RESULTS AND DISCUSSION}

RESULTS

Three different methods were used to evaluate the attenuation provided by an insert-type hearing protective device (E-A-R plug). All three methods used a real-ear-atthreshold procedure in which open and occluded threshold values were obtained at each test frequency; the difference between open and occluded threshold values yielded the attenuation value of the earplug at each frequency. The three methods used in this study included: (1) the use of one-third octave-band noise stimuli in sound-field; the use of pure-tone stimuli presented under the earphone/ support combination; and (3) the use of pure-tone stimuli presented under earphones only.

One-third octave-band nolse stimuli with center frequencies of $1000,2000,3150$, and $4000 \mathrm{~Hz}$ were used for method one of this study; for methods two and three, puretone stimuli of $1000,2000,3000$, and $4000 \mathrm{~Hz}$ were used. Thresholds were determined to the nearest decibel using a modified Hughson-Westlake, method-of-limits psychophysical procedure.

The data recorded for the E-A-R plug, using each of 
the three methods, consisted of three open and three occluded threshold levels at each test frequency for each test subject (see Appendix $c$ ). The attenuation values were calculated by subtracting the open threshold measurement from the occluded threshold measurement obtained during each trial. The attenuation values obtalned for each method are displayed in Tables IV through VI. 
TABLE IV

ATTENUATION VALUES OBTAINED USING ONE-THIRD OCTAVE-BAND NOISE STIMULI IN A SOUND-FIELD

\begin{tabular}{|c|c|c|c|c|c|}
\hline Subject & Trial & $1000 \mathrm{~Hz}$ & $2000 \mathrm{~Hz}$ & $3150 \mathrm{~Hz}$ & $4000 \mathrm{~Hz}$ \\
\hline 1 & $\begin{array}{l}1 \\
2 \\
3\end{array}$ & $\begin{array}{l}29 \\
28 \\
29\end{array}$ & $\begin{array}{l}32 \\
31 \\
31\end{array}$ & $\begin{array}{l}41 \\
44 \\
43\end{array}$ & $\begin{array}{l}41 \\
38 \\
45\end{array}$ \\
\hline 2 & $\begin{array}{l}1 \\
2 \\
3\end{array}$ & $\begin{array}{l}30 \\
30 \\
24\end{array}$ & $\begin{array}{l}33 \\
32 \\
29\end{array}$ & $\begin{array}{l}41 \\
36 \\
31\end{array}$ & $\begin{array}{l}42 \\
38 \\
35\end{array}$ \\
\hline 3 & $\begin{array}{l}1 \\
2 \\
3\end{array}$ & $\begin{array}{l}37 \\
34 \\
32\end{array}$ & $\begin{array}{l}37 \\
35 \\
36\end{array}$ & $\begin{array}{l}44 \\
44 \\
42\end{array}$ & $\begin{array}{l}41 \\
41 \\
41\end{array}$ \\
\hline 4 & $\begin{array}{l}1 \\
2 \\
3\end{array}$ & $\begin{array}{l}36 \\
40 \\
40\end{array}$ & $\begin{array}{l}37 \\
36 \\
37\end{array}$ & $\begin{array}{l}36 \\
46 \\
41\end{array}$ & $\begin{array}{l}41 \\
41 \\
41\end{array}$ \\
\hline 5 & $\begin{array}{l}1 \\
2 \\
3\end{array}$ & $\begin{array}{l}30 \\
32 \\
29\end{array}$ & $\begin{array}{l}31 \\
35 \\
33\end{array}$ & $\begin{array}{l}48 \\
47 \\
41\end{array}$ & $\begin{array}{l}44 \\
47 \\
41\end{array}$ \\
\hline 6 & $\begin{array}{l}1 \\
2 \\
3\end{array}$ & $\begin{array}{l}32 \\
34 \\
29\end{array}$ & $\begin{array}{l}35 \\
37 \\
37\end{array}$ & $\begin{array}{l}40 \\
42 \\
43\end{array}$ & $\begin{array}{l}41 \\
43 \\
37\end{array}$ \\
\hline 7 & $\begin{array}{l}1 \\
2 \\
3\end{array}$ & $\begin{array}{l}31 \\
31 \\
32\end{array}$ & $\begin{array}{l}35 \\
34 \\
33\end{array}$ & $\begin{array}{l}40 \\
43 \\
38\end{array}$ & $\begin{array}{l}45 \\
49 \\
40\end{array}$ \\
\hline 8 & $\begin{array}{l}1 \\
2 \\
3\end{array}$ & $\begin{array}{l}36 \\
33 \\
31\end{array}$ & $\begin{array}{l}31 \\
29 \\
30\end{array}$ & $\begin{array}{l}42 \\
47 \\
43\end{array}$ & $\begin{array}{l}42 \\
44 \\
45\end{array}$ \\
\hline 9 & $\begin{array}{l}1 \\
2 \\
3\end{array}$ & $\begin{array}{l}36 \\
33 \\
31\end{array}$ & $\begin{array}{l}33 \\
39 \\
35\end{array}$ & $\begin{array}{l}35 \\
36 \\
37\end{array}$ & $\begin{array}{l}39 \\
37 \\
35\end{array}$ \\
\hline 10 & $\begin{array}{l}1 \\
2 \\
3\end{array}$ & $\begin{array}{l}31 \\
35 \\
30\end{array}$ & $\begin{array}{l}33 \\
38 \\
31\end{array}$ & $\begin{array}{l}37 \\
38 \\
45\end{array}$ & $\begin{array}{l}40 \\
45 \\
43\end{array}$ \\
\hline Means & $\begin{array}{l}1 \\
2 \\
3\end{array}$ & $\begin{array}{l}32.8 \\
33.0 \\
30.7\end{array}$ & $\begin{array}{l}33.7 \\
34.6 \\
33.2\end{array}$ & $\begin{array}{l}40.4 \\
42.3 \\
40.4\end{array}$ & $\begin{array}{l}41.6 \\
42.3 \\
40.3\end{array}$ \\
\hline
\end{tabular}




\section{TABLE V}

ATTENUATION VALUES OBTAINED USING PURE-TONE SIGNALS PRESENTED UNDER EARPHONE/SUPPORT COMBINATION

\begin{tabular}{|c|c|c|c|c|c|}
\hline subject & Trial & $1000 \mathrm{~Hz}$ & $2000 \mathrm{~Hz}$ & $3150 \mathrm{~Hz}$ & $4000 \mathrm{~Hz}$ \\
\hline 1 & $\begin{array}{l}1 \\
2 \\
3\end{array}$ & $\begin{array}{l}26 \\
24 \\
28\end{array}$ & $\begin{array}{l}28 \\
28 \\
31\end{array}$ & $\begin{array}{l}44 \\
45 \\
44\end{array}$ & $\begin{array}{l}49 \\
50 \\
47\end{array}$ \\
\hline 2 & $\begin{array}{l}1 \\
2 \\
3\end{array}$ & $\begin{array}{l}26 \\
28 \\
30\end{array}$ & $\begin{array}{l}33 \\
30 \\
28\end{array}$ & $\begin{array}{l}46 \\
42 \\
38\end{array}$ & $\begin{array}{l}42 \\
41 \\
37\end{array}$ \\
\hline 3 & $\begin{array}{l}1 \\
2 \\
3\end{array}$ & $\begin{array}{l}29 \\
25 \\
25\end{array}$ & $\begin{array}{l}31 \\
29 \\
33\end{array}$ & $\begin{array}{l}46 \\
44 \\
41\end{array}$ & $\begin{array}{l}48 \\
45 \\
42\end{array}$ \\
\hline 4 & $\begin{array}{l}1 \\
2 \\
3\end{array}$ & $\begin{array}{l}36 \\
36 \\
37\end{array}$ & $\begin{array}{l}38 \\
34 \\
38\end{array}$ & $\begin{array}{l}38 \\
43 \\
44\end{array}$ & $\begin{array}{l}42 \\
43 \\
44\end{array}$ \\
\hline 5 & $\begin{array}{l}1 \\
2 \\
3\end{array}$ & $\begin{array}{l}36 \\
33 \\
28\end{array}$ & $\begin{array}{l}31 \\
38 \\
33\end{array}$ & $\begin{array}{l}45 \\
49 \\
47\end{array}$ & $\begin{array}{l}48 \\
50 \\
52\end{array}$ \\
\hline 6 & $\begin{array}{l}1 \\
2 \\
3\end{array}$ & $\begin{array}{l}33 \\
32 \\
27\end{array}$ & $\begin{array}{l}35 \\
31 \\
31\end{array}$ & $\begin{array}{l}42 \\
41 \\
39\end{array}$ & $\begin{array}{l}51 \\
53 \\
43\end{array}$ \\
\hline 7 & $\begin{array}{l}1 \\
2 \\
3\end{array}$ & $\begin{array}{l}29 \\
37 \\
28\end{array}$ & $\begin{array}{l}26 \\
30 \\
28\end{array}$ & $\begin{array}{l}47 \\
44 \\
43\end{array}$ & $\begin{array}{l}43 \\
49 \\
43\end{array}$ \\
\hline 8 & $\begin{array}{l}1 \\
2 \\
3\end{array}$ & $\begin{array}{l}35 \\
31 \\
30\end{array}$ & $\begin{array}{l}36 \\
32 \\
29\end{array}$ & $\begin{array}{l}48 \\
44 \\
43\end{array}$ & $\begin{array}{l}47 \\
51 \\
46\end{array}$ \\
\hline 9 & $\begin{array}{l}1 \\
2 \\
3\end{array}$ & $\begin{array}{l}32 \\
36 \\
30\end{array}$ & $\begin{array}{l}39 \\
36 \\
35\end{array}$ & $\begin{array}{l}43 \\
42 \\
43\end{array}$ & $\begin{array}{l}36 \\
33 \\
40\end{array}$ \\
\hline 10 & $\begin{array}{l}1 \\
2 \\
3\end{array}$ & $\begin{array}{l}31 \\
34 \\
37\end{array}$ & $\begin{array}{l}34 \\
35 \\
35\end{array}$ & $\begin{array}{l}48 \\
48 \\
48\end{array}$ & $\begin{array}{l}45 \\
47 \\
51\end{array}$ \\
\hline Means & $\begin{array}{l}1 \\
2 \\
3\end{array}$ & $\begin{array}{l}31.3 \\
31.6 \\
30.0\end{array}$ & $\begin{array}{l}33.1 \\
32.3 \\
32.1\end{array}$ & $\begin{array}{l}44.7 \\
44.2 \\
43.0\end{array}$ & $\begin{array}{l}45.1 \\
46.2 \\
44.5\end{array}$ \\
\hline
\end{tabular}


TABLE VI

ATTENUATION VALUES OBTAINED USING PURE-TONE SIGNALS PRESENTED UNDER EARPHONES ONLY

\begin{tabular}{|c|c|c|c|c|c|}
\hline subject & Trial & $1000 \mathrm{~Hz}$ & $2000 \mathrm{~Hz}$ & $3150 \mathrm{~Hz}$ & $4000 \mathrm{~Hz}$ \\
\hline 1 & $\begin{array}{l}1 \\
2 \\
3\end{array}$ & $\begin{array}{l}33 \\
30 \\
32\end{array}$ & $\begin{array}{l}31 \\
33 \\
30\end{array}$ & $\begin{array}{l}48 \\
47 \\
43\end{array}$ & $\begin{array}{l}48 \\
41 \\
45\end{array}$ \\
\hline 2 & $\begin{array}{l}1 \\
2 \\
3\end{array}$ & $\begin{array}{l}24 \\
24 \\
27\end{array}$ & $\begin{array}{l}38 \\
31 \\
30\end{array}$ & $\begin{array}{l}49 \\
43 \\
35\end{array}$ & $\begin{array}{l}48 \\
39 \\
36\end{array}$ \\
\hline 3 & $\begin{array}{l}1 \\
2 \\
3\end{array}$ & $\begin{array}{l}25 \\
20 \\
22\end{array}$ & $\begin{array}{l}35 \\
34 \\
37\end{array}$ & $\begin{array}{l}42 \\
40 \\
40\end{array}$ & $\begin{array}{l}43 \\
39 \\
40\end{array}$ \\
\hline 4 & $\begin{array}{l}1 \\
2 \\
3\end{array}$ & $\begin{array}{l}45 \\
38 \\
46\end{array}$ & $\begin{array}{l}42 \\
40 \\
47\end{array}$ & $\begin{array}{l}35 \\
35 \\
40\end{array}$ & $\begin{array}{l}39 \\
41 \\
37\end{array}$ \\
\hline 5 & $\begin{array}{l}1 \\
2 \\
3\end{array}$ & $\begin{array}{l}25 \\
35 \\
40\end{array}$ & $\begin{array}{l}35 \\
39 \\
43\end{array}$ & $\begin{array}{l}45 \\
45 \\
44\end{array}$ & $\begin{array}{l}49 \\
50 \\
46\end{array}$ \\
\hline 6 & $\begin{array}{l}1 \\
2 \\
3\end{array}$ & $\begin{array}{l}30 \\
30 \\
27\end{array}$ & $\begin{array}{l}36 \\
33 \\
39\end{array}$ & $\begin{array}{l}40 \\
44 \\
48\end{array}$ & $\begin{array}{l}48 \\
51 \\
57\end{array}$ \\
\hline 7 & $\begin{array}{l}1 \\
2 \\
3\end{array}$ & $\begin{array}{l}27 \\
37 \\
32\end{array}$ & $\begin{array}{l}29 \\
35 \\
34\end{array}$ & $\begin{array}{l}36 \\
37 \\
36\end{array}$ & $\begin{array}{l}37 \\
43 \\
45\end{array}$ \\
\hline 8 & $\begin{array}{l}1 \\
2 \\
3\end{array}$ & $\begin{array}{l}27 \\
30 \\
30\end{array}$ & $\begin{array}{l}40 \\
39 \\
35\end{array}$ & $\begin{array}{l}37 \\
47 \\
40\end{array}$ & $\begin{array}{l}47 \\
48 \\
45\end{array}$ \\
\hline 9 & $\begin{array}{l}1 \\
2 \\
3\end{array}$ & $\begin{array}{l}30 \\
39 \\
42\end{array}$ & $\begin{array}{l}40 \\
40 \\
40\end{array}$ & $\begin{array}{l}37 \\
41 \\
45\end{array}$ & $\begin{array}{l}46 \\
41 \\
48\end{array}$ \\
\hline 10 & $\begin{array}{l}1 \\
2 \\
3\end{array}$ & $\begin{array}{l}30 \\
33 \\
35\end{array}$ & $\begin{array}{l}35 \\
39 \\
39\end{array}$ & $\begin{array}{l}37 \\
39 \\
43\end{array}$ & $\begin{array}{l}41 \\
43 \\
47\end{array}$ \\
\hline Means & $\begin{array}{l}1 \\
2 \\
3\end{array}$ & $\begin{array}{l}29.6 \\
31.6 \\
33.3\end{array}$ & $\begin{array}{l}36.1 \\
36.3 \\
37.4\end{array}$ & $\begin{array}{l}40.6 \\
41.8 \\
41.4\end{array}$ & $\begin{array}{l}44.6 \\
43.6 \\
44.6\end{array}$ \\
\hline
\end{tabular}


Table VII summarizes the means and standard deviations obtained for each test frequency using each of the three methods.

\section{TABLE VII}

ATtenuation VALUES - MEANS AND STANDARD DEVIATIONS

$\begin{array}{lrrrr} & 1000 \mathrm{~Hz} & 2000 \mathrm{~Hz} & 3000 \mathrm{~Hz} & 4000 \mathrm{~Hz} \\ \text { Soundfleld } & 32.17 & 33.83 & 41.03 & 41.40 \\ & 3.50 & 2.77 & 4.03 & 3.30 \\ \text { Earphone/support } & 30.93 & 32.50 & 43.97 & 45.27 \\ \quad \text { combination } & 4.06 & 3.52 & 2.93 & 4.93 \\ \text { Earphones only } & 31.50 & 36.60 & 41.27 & 44.27 \\ & 6.56 & 4.26 & 4.32 & 4.83\end{array}$

The attenuation values obtained in this study were subjected to a repeated measures, multivarlate analysis of variance (MANOVA) with three within-subject factors (trial, method, and frequency). Results generated using the pillais Multivariate Test of Significance are listed in Table VIII. The final column, sig. of F, represents the observed significance level for that analysis. The observed significance level is the probability that a difference at least as large as the one observed would have arisen if the population variances were really equal (Norusis, 1983).

The results of this analysis revealed a significant main effect of frequency $(p<.01)$. No other results were significant at the 0.01 level; however, the method by frequency interaction was significant at the .02 level. This suggests that there are significant differences in 
TABLE VIII

RESULTS OF THE PILLAIS MULTIVARIATE TEST OF SIGNIFICANCE

$\begin{array}{lcrcrc}\text { Source } & \begin{array}{c}\text { Value of } \\ \text { Test Stat }\end{array} & \text { Exact F } & \begin{array}{c}\text { Hypothesis } \\ \text { D.F. }\end{array} & \begin{array}{c}\text { Exror } \\ \text { D.F. }\end{array} & \begin{array}{l}\text { Sig. } \\ \text { of F }\end{array} \\ \text { Main Effects } & & & & & \\ \quad \text { Trial } & .19924 & .99527 & 2.0 & 8.0 & .411 \\ \quad \begin{array}{l}\text { Method } \\ \text { Frequency }\end{array} & .31704 & 1.85684 & 2.0 & 8.0 & .218 \\ & .87047 & 15.67896 & 3.0 & 7.0 & .002\end{array}$

\section{Two-Way}

Interactions

$\begin{array}{lrrrrr}\text { Trial/Method } & .51664 & 1.60330 & 4.0 & 6.0 & .288 \\ \text { Trial/Freq } & .27336 & .25080 & 6.0 & 4.0 & .935 \\ \text { Method/Freq } & .93358 & 9.37093 & 6.0 & 4.0 & .024\end{array}$

Three-Way

Interaction

Trial/Meth/Freq - Multivariate results not calculated. Univariate results, $F=1.0$ (df 12) .456

attenuation values obtained using the different methods depending on the frequency tested.

The central question this study was designed to answer is: Does the use of alternate methods of measuring the attenuation provided by insert-type hearing protective devices yield results which are significantly different than those obtained using the standard sound-field method? To more clearly answer this question, a priori (planned) comparisons between the standard and alternate methods were conducted at each test Exequency. The comparisons of interest were between sound-field and earphone/support methods and between sound-field and earphone only methods at each frequency. Because these comparisons were $11 \mathrm{mited}$ in number, simple comparison procedures (paired t-tests) were used rather than multiple comparison procedures (such as 
Newman-Keul's) when comparing means. The results of the paired t-tests for each frequency are listed in Table IX. The results of these t-tests revealed several significant differences between attenuation values obtained using the different methods. Signiflcant differences ( $p<.01$ ) between the sound-field method and the earphone/ support method were found at 3000 and $4000 \mathrm{~Hz}$. significant differences between the sound-field and earphones-only method were found at 2000 and $4000 \mathrm{~Hz}$.

Attenuation values, averaged over the three trials obtained, for each subject are listed in Appendix D. These values are arranged by frequency and method for each subject. 
TABLE IX

RESULTS OF PAIRED T-TESTS COMPARING TEST METHODS

\begin{tabular}{|c|c|c|c|c|c|c|c|c|}
\hline $\begin{array}{l}\text { Variable* } \\
\overline{1000}-\overline{H z} \\
100- \\
\text { SF Atten }\end{array}$ & Mean & $\begin{array}{l}\text { Std } \\
\text { Dev } \\
---\end{array}$ & $\begin{array}{l}\text { Std } \\
\text { Err } \\
--\end{array}$ & $\begin{array}{r}\text { Diff } \\
\text { Mean } \\
-\quad-\quad-\end{array}$ & $\begin{array}{l}\text { std } \\
\text { Dev } \\
---\end{array}$ & $\begin{array}{l}\text { std } \\
\text { Err } \\
--\end{array}$ & $\begin{array}{r}\text { Value } \\
(D . F .) \\
----\end{array}$ & $\begin{array}{l}\text { 2-Ta11 } \\
\text { Prob } \\
---\end{array}$ \\
\hline $\begin{array}{l}\mathrm{EP} / \mathrm{S} \text { Atten } \\
\overline{1000} \mathrm{~Hz} \\
\text { SF Atten }\end{array}$ & $\begin{array}{r}30.9 \\
---\end{array}$ & 4.1 & $\begin{array}{r}.74 \\
-\quad-\end{array}$ & $\begin{array}{r}1.2 \\
-\quad--\end{array}$ & $\begin{array}{r}3.9 \\
-\quad--\end{array}$ & $\begin{array}{l}.71 \\
--\end{array}$ & $\begin{array}{l}1.68 \\
(29) \\
-\quad--\end{array}$ & $\begin{array}{l}0.103 \\
---\end{array}$ \\
\hline $\begin{array}{l}\text { EP Atten } \\
-\overline{-}-- \\
2000 \mathrm{~Hz} \\
\text { SF Atten }\end{array}$ & $\begin{array}{r}31.5 \\
-. \\
33.8\end{array}$ & 6.6 & 1.19 & $\begin{array}{r}.67 \\
---\end{array}$ & $\begin{array}{r}6.4 \\
---\end{array}$ & $\begin{array}{l}1.17 \\
-.-\end{array}$ & $\begin{array}{c}0.57 \\
(29) \\
----\end{array}$ & $\begin{array}{l}0.575 \\
-.-\end{array}$ \\
\hline $\begin{array}{l}\text { EP/S Atten } \\
-10-0 \mathrm{~Hz} \\
2000 \\
\text { SF Atten }\end{array}$ & 32.5 & 3.5 & $\begin{array}{r}.64 \\
-\quad-\end{array}$ & $\begin{array}{r}1.33 \\
-\quad--\end{array}$ & 3.6 & $\begin{array}{l}.654 \\
-.-\end{array}$ & $\begin{array}{r}2.04 \\
(29) \\
-\quad-\quad-\end{array}$ & $\begin{array}{l}0.051 \\
-.-\end{array}$ \\
\hline
\end{tabular}

$\overline{3000} \mathrm{~Hz}$

SF Atten $\quad 41.0 \quad 4.0 \quad .74$

EP/S Atten $43.9 \quad 2.9 \quad .54 \begin{array}{lllllll}-2.93 & 3.9 & .716 & -4.10 & 0.000\end{array}$ $\overline{3000} \mathrm{~Hz}$

SF Atten $41.0 \quad 4.0 \quad .74$

$\begin{array}{lllllllll}\text { EP Atten } & 41.3 & 4.3 & .80^{-0.23} & 4.4 & .810 & -0.29\end{array}$

0.775

$\overline{4000} \mathrm{~Hz}$

SF Atten $\quad 41.4 \quad 3.3 \quad .60$

EP/S Atten $45.3 \quad 4.9 \quad .90 \begin{array}{llllll}-3.9 & 4.0 & .735 & -5.26 & 0.000\end{array}$

$\overline{4000} \mathbf{H z}$

SF Atten $\quad 41.4 \quad 3.3 \quad .60$

EP/S Atten $44.27 \quad 4.8 \quad .88 \begin{array}{rrrrrr}-2.9 & 5.5 & 1.00 & -2.86 & 0.008\end{array}$

* SF Atten = Attenuation values for sound-field method $\mathrm{EP} / \mathrm{S}$ Atten = Attenuation values for earphone/support method EP Atten = Attenuation values for earphones-only method 


\section{DISCUSSION}

The attenuation values obtained using one-third octaveband noise stimuli presented in a sound-fleld are considered the "true" attenuation values for the E-A-R plug used in this study. This test method conforms to the specifications outlined in the Method for the Measurement of the Real-Ear Attenuation of Hearing Protectors (ANSI s12.6-1984). The "sound-fiela" attenuation values obtained during this study do not equal the manufacturer's published attenuation values for the E.A.R. plug, but do agree closely with values obtained by previous investigators in the fleld; rable $x$ compares manufacturer data with data obtained in the present study and data obtalned in two other studies. A possible reason for this discrepancy is that the attenuation values listed by the manufacturer are obtained using subjects experienced in participating in hearing protector attenuation tests; subjects in this study and other field studies were probably less experienced.

In addition to the sound-field method, two other test methods were used in this study. The "earphone/support" method was conducted using pure-tone signals presented under standard audiometer earphones placed over a circumaural earphone supporting device specially designed for this study. The "earphones-only" method was conducted using pure-tone signals presented under standard audiometric earphones (TDH-39 drivers mounted in MX 11/AR cushions). 
TABLE $x$

MANUPACTURER AND FIELD ATTENUATION DATA

FOR THE E-A-R PLUG

Attenuation values are expressed in terms of means and standard deviations (in parentheses) at each one-third octave-band center test frequency.

$1000 \mathrm{~Hz} \quad 2000 \mathrm{~Hz} \quad 3000 \mathrm{~Hz} \quad 4000 \mathrm{~Hz}$

$\begin{array}{lllll}\text { Manufacturer data } & 40.3 & 41.8 & 44.6 & 45.3 \\ & (1.7) & (2.1) & (1.9) & (1.7) \\ \text { Current study } & 32.17 & 33.83 & 41.03 & 41.40 \\ & (3.5) & (2.8) & (4.0) & (3.3) \\ & & & & \\ \text { Michael, et. al.. } & 34.3 & 32.9 & 39.9 & 40.6 \\ \quad(1976) & (5.7) & (3.6) & (2.1) & (3.1) \\ \begin{array}{r}\text { Berger, } \\ (1984)\end{array} & --- & 36.0 & --- & 40.3 \\ & & (3.7) & & (4.6)\end{array}$

The circumaral earphone supporting device used in this study was designed to keep the audiometer earphones from resting directiy on the pinna and altering the fit of the

earplug being tested. Comparing the results of this test method with the "true" attenuation values obtained using the sound-fleld method, significant differences $(p<.01)$ were found at 3000 and $4000 \mathrm{~Hz}$. At these frequencles, the earphone/support combination yielded significantly higher attenuation values. Figure 8 illustrates these differences. These signiflcant differences may be related to the use of pure-tone stimuli with the earphone/support combination. Webster, et al., (1956), comparing REAT results for noise band and pure-tone stimuli, found that the use of bands of noise or the use of pure-tones ylelded results that were 


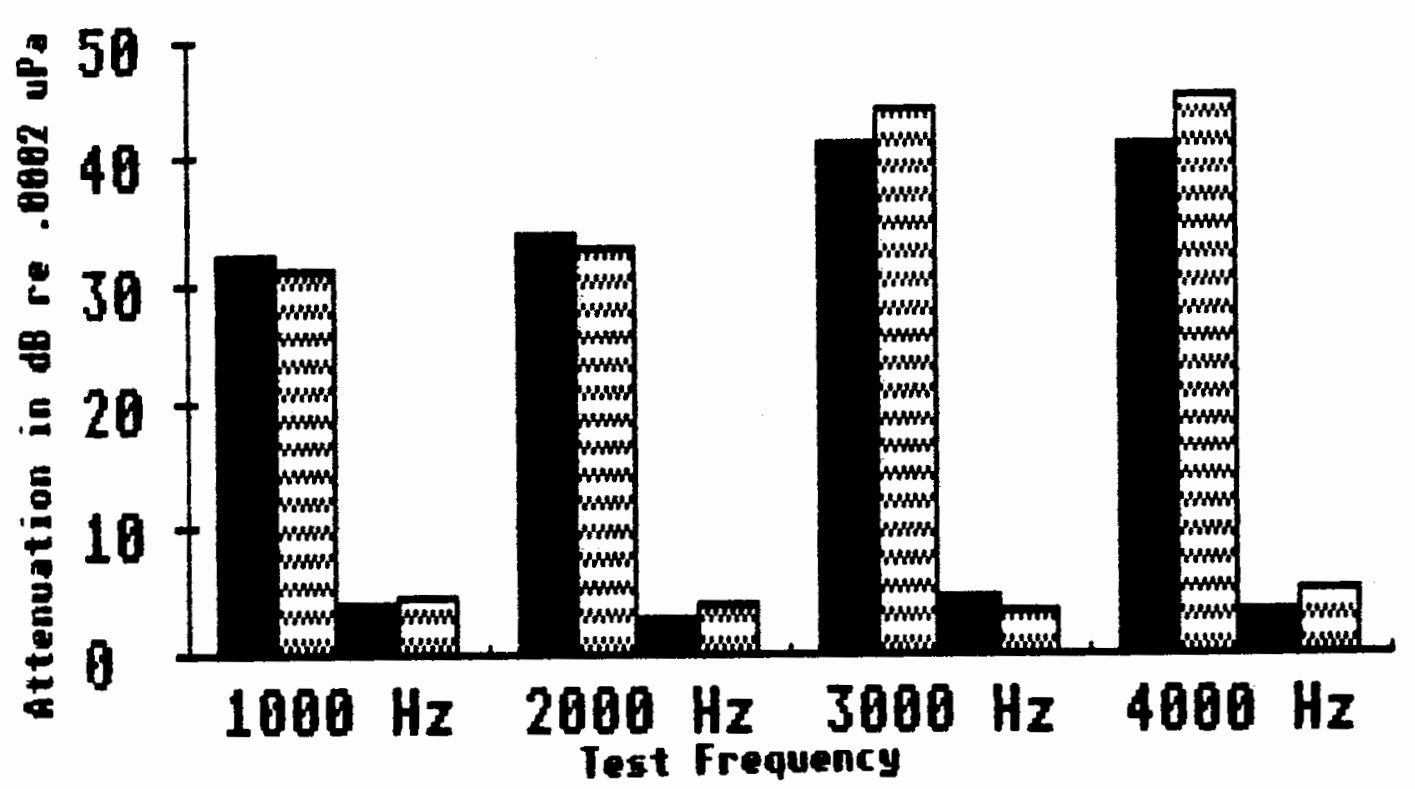

Eiqure 8. Means (tall bars) and standard deviations (short bars) for the soundfield method (solid bars) and the earphone/support method (patterned bars).

essentially the same except around $4000 \mathrm{~Hz}$, where pure-tone attenuation was higher; Webster's data for both nolse-band and pure-tone stimuli were obtained under sound-field test conditions and no explanations were advanced for the differences observed. The difference found in the present study could possibly be related to resonances occuring within the cavity of air enclosed by the earphone/support combination; such resonances could change between the open and occluded test conditions due to the insertion of the earplug into the ear canal. Such a difference could also be related to improper placement of the earphone diaphragm over the opening of the earphone supporting device resulting in a reduction in the effective sound pressure level delivered to the ear, although special care was taken to avold this 
problem.

Looking at the data obtained for individual subjects at each of the frequencles (see Appendix D) and comparing the results obtained using the sound-field method versus the earphone/support combination method, one can see that the best agreement between methods occurs at 1000 and $2000 \mathrm{~Hz}$. In Elgures 9 through 12, averaged attenuation values for each subject using each of the alternate methods are plotted as a function of the "true" attenuation values obtained using the sound-field method. The solid diagonal line (slope 1/1) indicates perfect correlation between the standard and alternate values. Values falling below the diagonal line represent subjects for whom the alternate method(s) resulted in underestimates of the "true" attenuation, while values falling above the diagonal line represent overestimates of "true" attenuation.

For eight of the ten subjects tested at $1000 \mathrm{~Hz}$, and for six of the ten subjects tested at $2000 \mathrm{~Hz}$, the use of the earphone/support combination yielded attenuation values that were equal to or slightly less than the values obtained using the sound-field method. At $3000 \mathrm{~Hz}$ and $4000 \mathrm{~Hz}$, however, the use of the earphone/support combination method consistently overestimated the "true" attenuation values obtained in sound-field testing. In most cases, these differences were slight but differences as great as 9 dB were observed. These observations are supported by Information reported by Berger (1984). Noting the results 


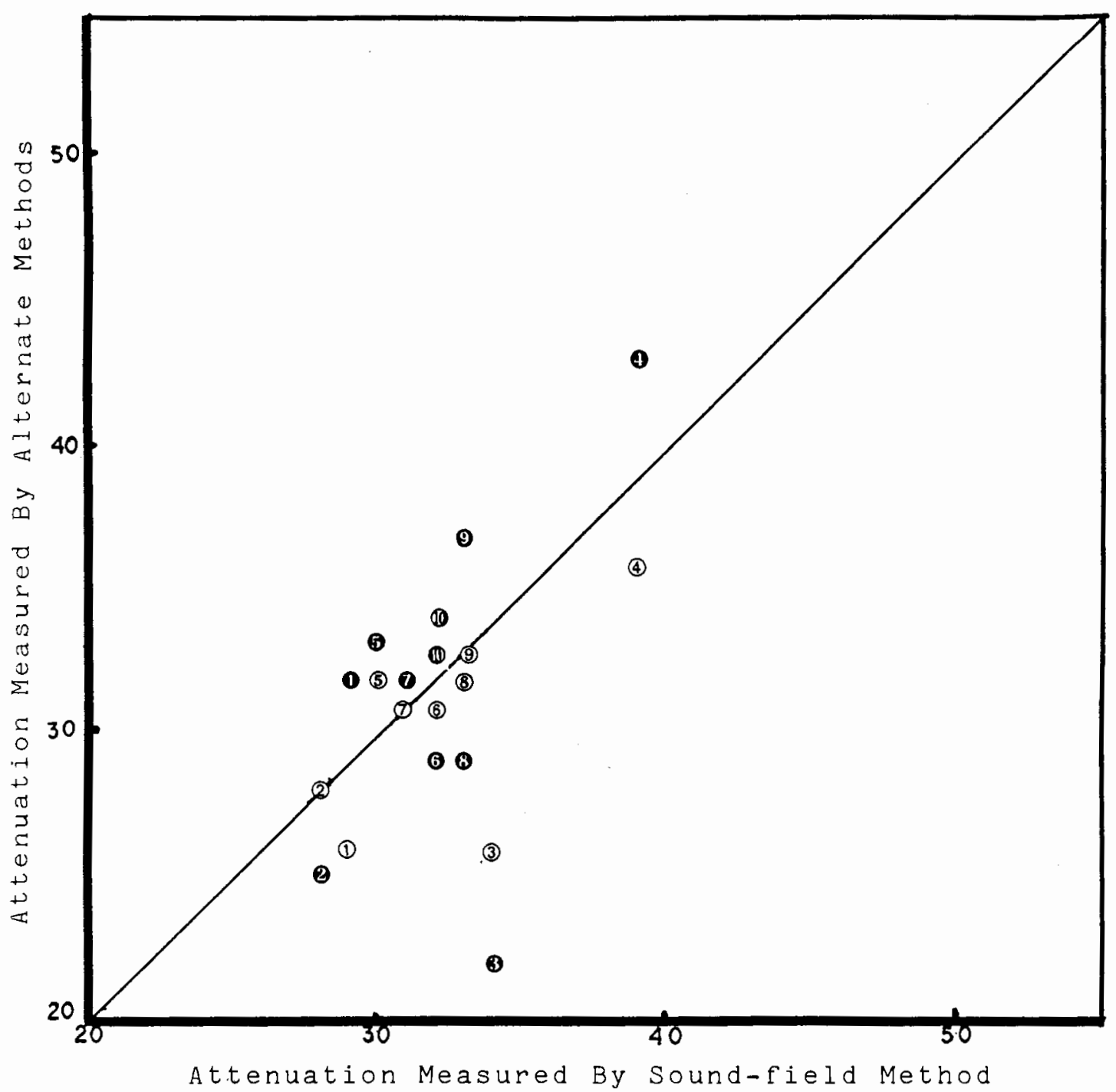

Elqure 9. Attenuation values for each subject at $1000 \mathrm{~Hz}$, with attenuation values obtained using alternate methods plotted as a function of attenuation values obtained using the sound-fleld method. subjects numbered 1 through 10 . Open circles ( ) represent values obtained using the earphone/support method. Filled circles (, represent values obtalned using the earphones-only method. 


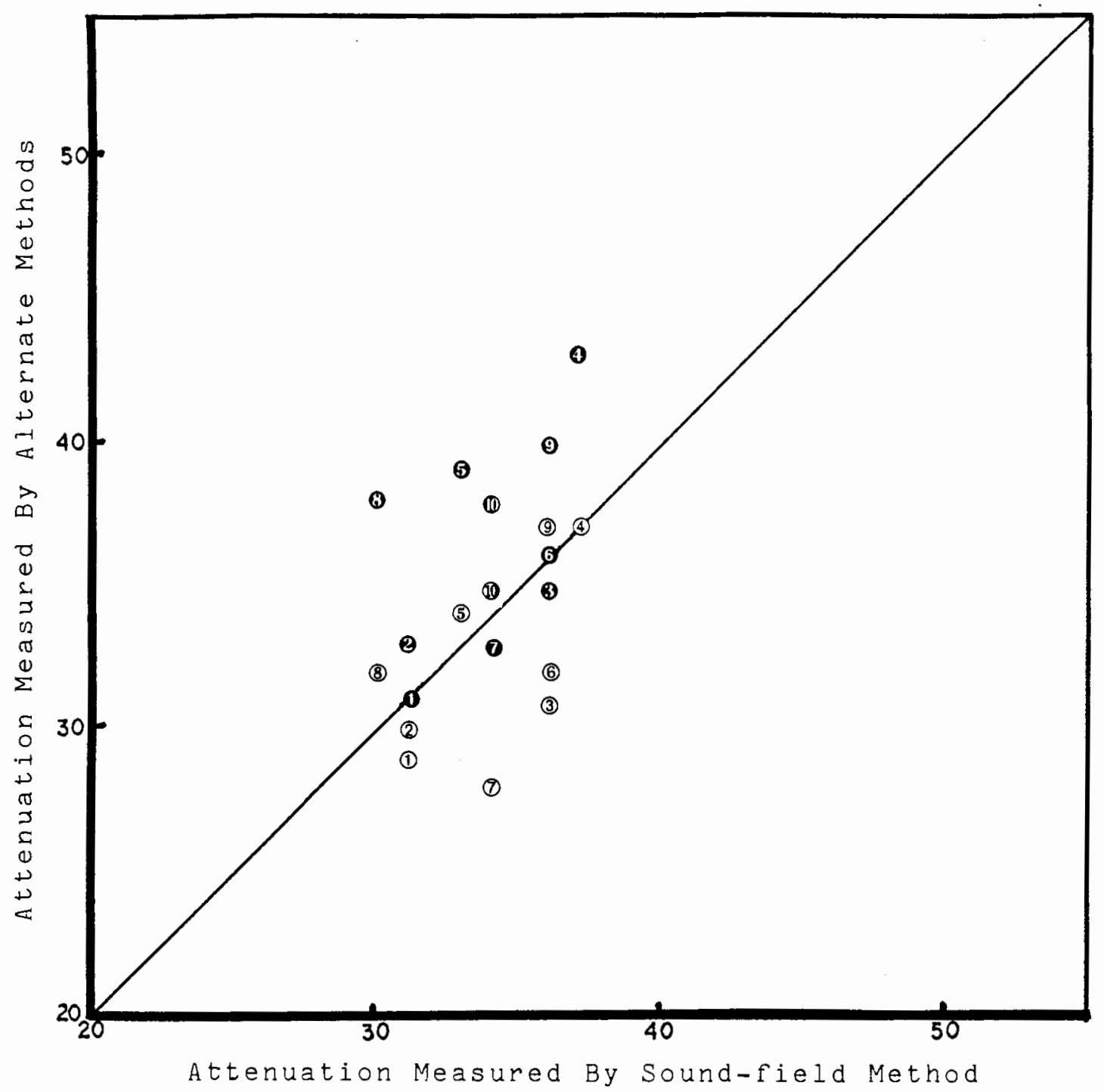

Elqure 10. Attenuation values for each subject at $2000 \mathrm{~Hz}$, with attenuation values obtained using alternate methods plotted as a function of attenuation values obtained using the sound-field method. subjects numbered 1 through 10. Open circles (, represent values obtained using the earphone/support method. Filled circles (, represent values obtained using the earphones-only method. 


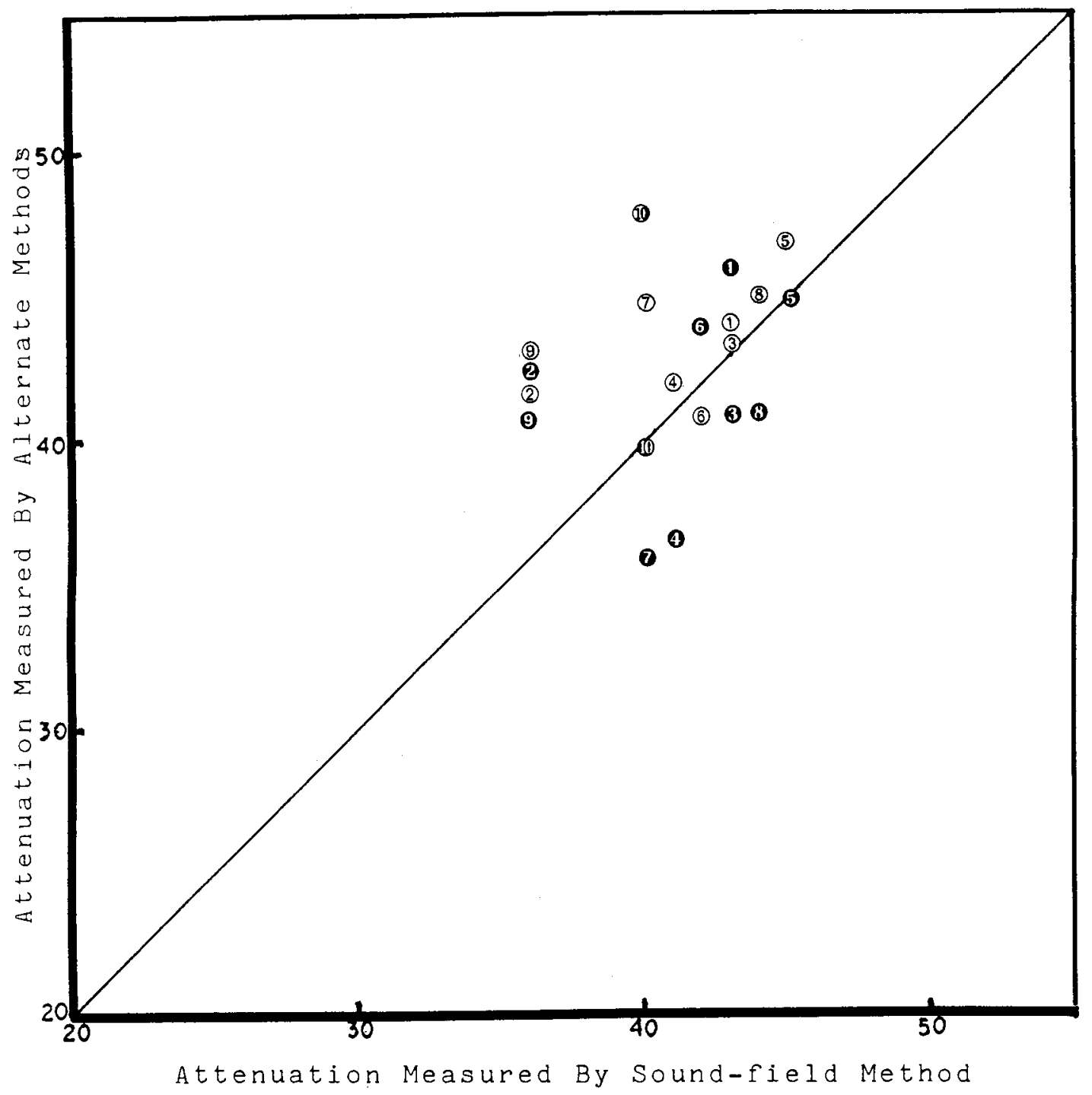

Fiqure 11. Attenuation values for each subject at $3000 \mathrm{~Hz}$, with attenuation values obtained using alternate methods plotted as a function of attenuation values obtained using the sound-field method. subjects numbered 1 through 10. Open circles ( ) represent values obtained using the earphone/support method. Filled circles (, represent values obtained using the earphones-only method. 


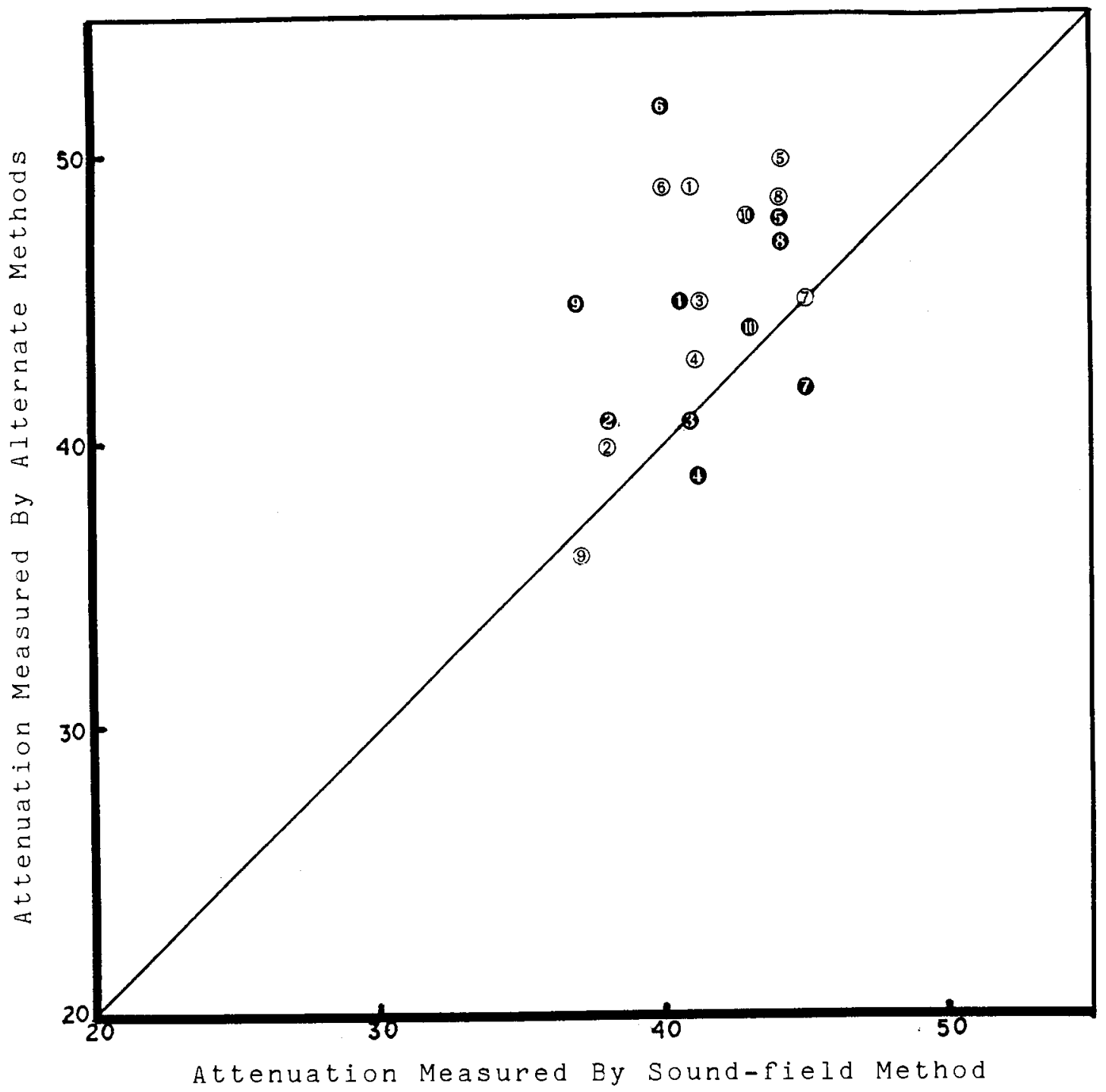

Elqure 12. Attenuation values for each subject at $4000 \mathrm{~Hz}$, with attenuation values obtained using alternate methods plotted as a function of attenuation values obtained using the sound-field method. Subjects numbered 1 through 10. Open circles $($, represent values obtained using the earphone/support method. Filled circles (, represent values obtained using the earphones-only method. 
of a study conducted by Fleming, Berger reported that 1000 Hz provided the best correlation between attenuation values measured in a sound-field and attenuation values obtained using NIOSH-type headphones. This may be fortultous, since typical noise-induced losses in hearing sensitivity would be less affected at lower frequencles than at higher frequencies.

Comparing the results of the "earphones-only" method with the "true" attenuation values obtained using the soundfleld method, significant differences $(p<.01)$ were found at 2000 and $4000 \mathrm{~Hz}$ (see Figure 13). Agaln, looking at the data obtained for individual subjects at each frequency (Appendix $D$ and Figures 9 through 12), it appears that the earphones-only method consistently overestimates the "true" attenuation of the earplug as measured by the sound-field test method. At $4000 \mathrm{~Hz}$, the true attenuation values were overestimated by as much as $12 \mathrm{~dB}$. Also, the standard deviations obtained for the earphones-only method were larger, in general, than for either the sound-fleld or the earphone/support methods, suggesting greater variability with the use of this method (see Figure 14). The best agreement between the sound-field data and the earphones only data occurred at $1000 \mathrm{~Hz}$, whlch is again in agreement with the information reported by Berger (1984).

Because of the limited scope of this study, any conclusions drawn from the data obtained must be tentative. The results of this study do, however, support the use of 


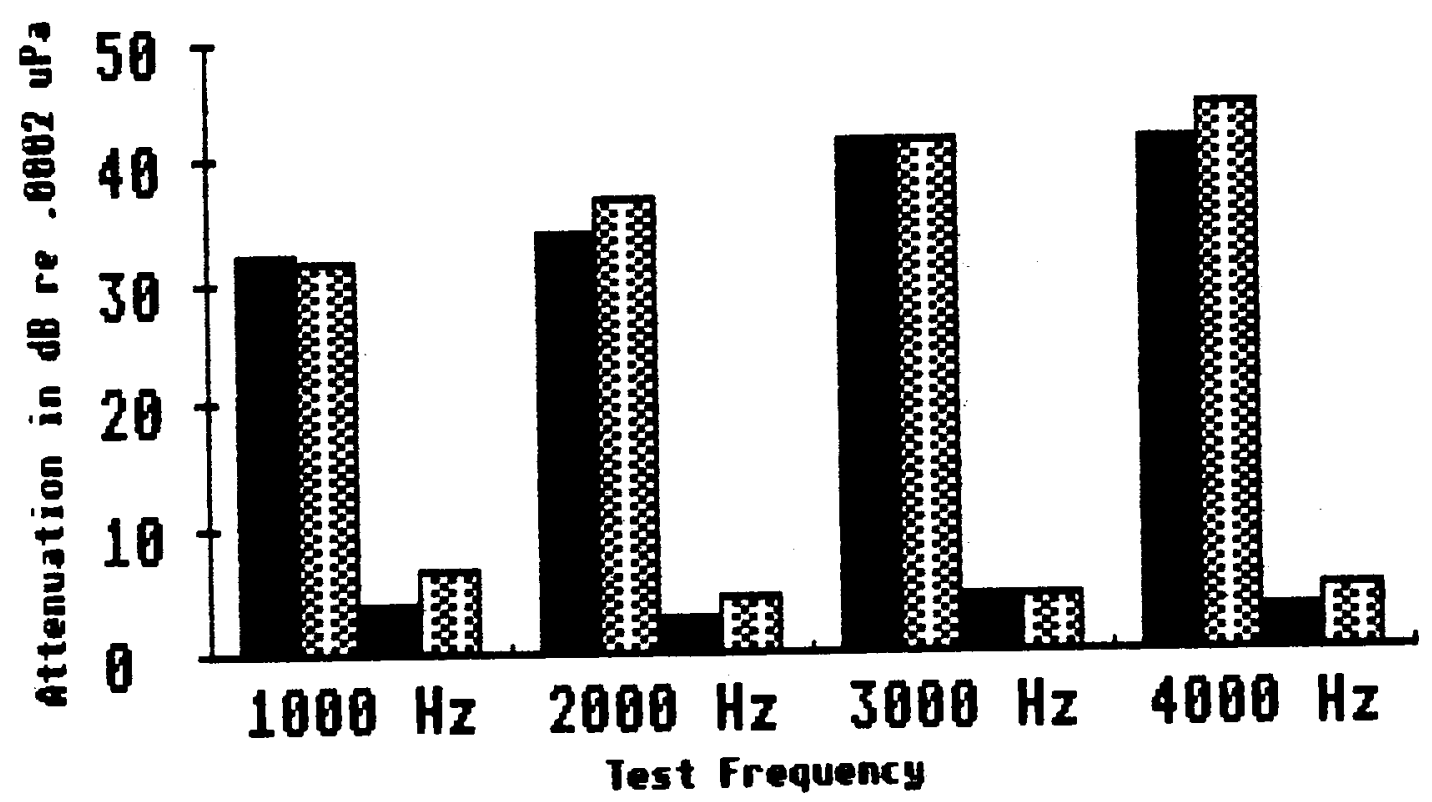

Fiqure 13. Means (tall bars) and standard deviations (short bars) for the soundfield method (solid bars) and the earphone/support method (patterned bars).

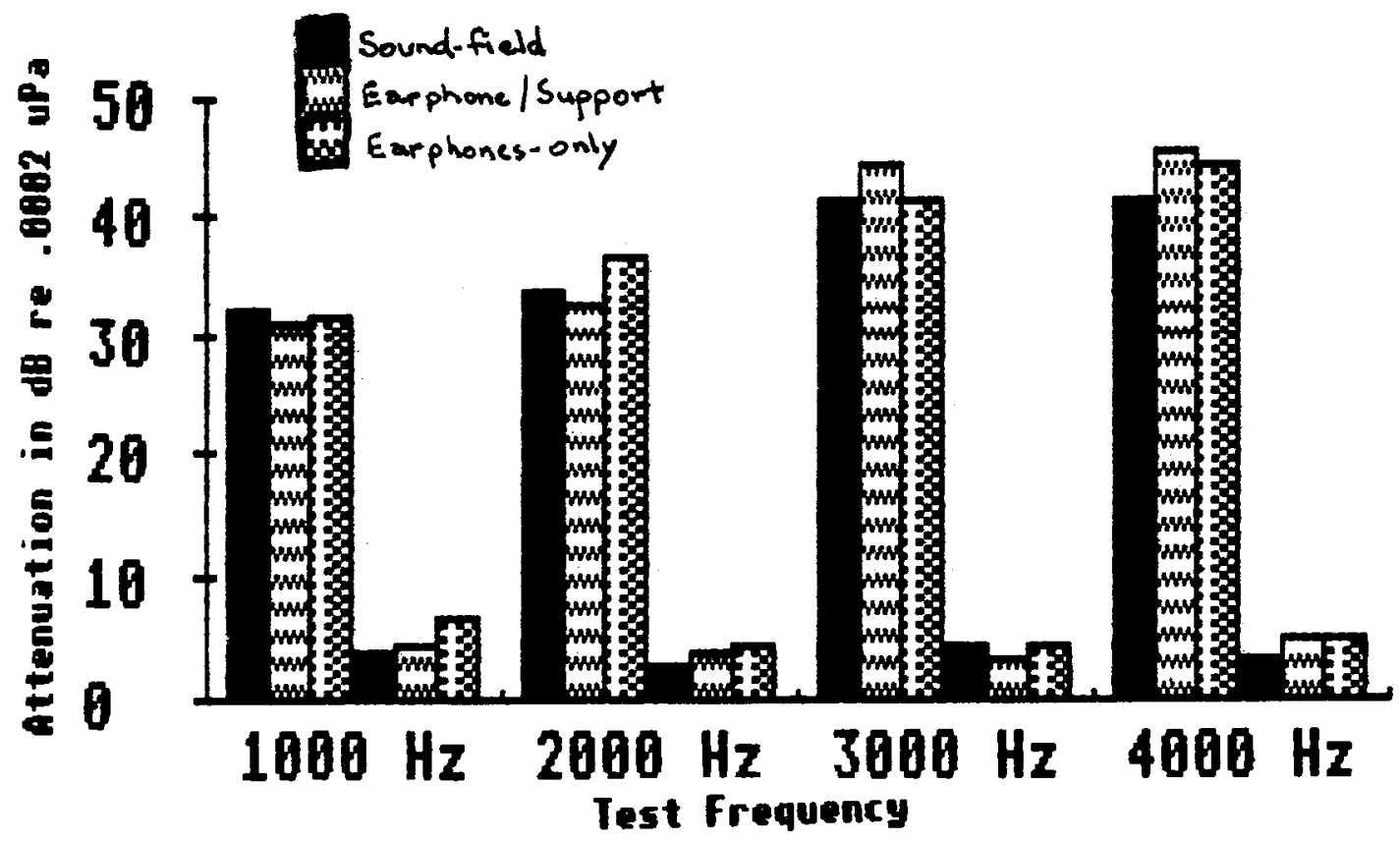

Fiqure 14. Means (tall bars) and standard deviations (short bars) Eor all three test methods. 
both the earphone/support method and the earphones-only method for measuring the attenuation provided by expandable foam insert-type hearing protectors if such testing is limited to those frequencles which show no significant differences from the sound-field method.

The single "best" frequency for testing is considered to be $1000 \mathrm{~Hz}$, as it yields the closest agreement with the "true" sound-field attenuation values. Testing at only $1000 \mathrm{~Hz}$ and/or $2000 \mathrm{~Hz}$ could yleld an adequate evaluation of total attenuation, if it is assumed that attenuation Increases with frequency (Royster \& Royster, 1985). If adequate attenuation values are obtained at 1000 and $2000 \mathrm{~Hz}$, attenuation values at higher frequencles could be considered to be within acceptable limits.

Testing at $4000 \mathrm{~Hz}$ is not recommended with either of the two alternate methods, as the use of pure-tone stimuli may result in overestimates of attenuation. In addition, testing at $4000 \mathrm{~Hz}$ could be unsuitable in "real world" situations due to the likelihood of encountering signiflcant hearing loss at that frequency. This could create a situation in which the test equipment would not have sufficiently high output levels to determine thresholds in the occluded condition, where sound levels must be high. This is especially true of the earphone/support method, as It required anywhere from 5 to $15 \mathrm{~dB}$ HL greater intensity to obtain thresholds in both the open and occluded conditions. This is possibly due to the absorption of energy by the foam 
material of the earphone supporting device itself and due to the greater distance from the earphone diaphragm to the tympanic membrane, which results in a larger enclosed volume of air and a resulting reduction of sound energy delivered to the eardrum.

Even though the earphones-only method, when compared to the sound-field method, yielded significant differences in attenuation values at only 2000 and $4000 \mathrm{~Hz}$, this method consistently yielded results that tended to overestimate the "true" attenuation of the earplugs. This would make the earphones-only method less desirable for use in the industrial setting because such results could lead employees to belleve that they are receiving adequate attenuation from their earplugs when they are not.

While both the earphone/support method and the earphones-only method can be considered sultable for use with expandable foam insert-type hearing protectors, the use of these methods with other types of insert-type hearingprotective devices remains to be determined. The fit of premolded earplugs, custom molded earplugs, or any earplugs that have handles which extend from the outer ear canal may be affected by use of the earphone/support test method or the earphones only test method. It is especially likely that the earphones only test method may affect the attenuation values obtained from these types of earplugs due to the alteration of fit resulting from the earphones resting on the pinna and the earplug itself. Further 
study is needed to determine the applicability of these test methods to other types of insert-type hearing-protective devices before these methods can be tested in the field. 


\section{CHAPTER V}

\section{SUMMARY AND IMPLICATIONS}

\section{SUMMARY}

To effectively implement an occupational hearing conservation program, employers must know the amount of attenuation (nolse reduction) provided by the hearingprotective devices used by their employees. Currently standardized test methods, performed under laboratory conditions, cannot be easily implemented in industrial settIngs, and previously proposed fleld methods have depended upon the use of special headphones which are not typically avallable in the workplace. These problems have led many occupational hearing conservationists to use standard audiometric headphones to evaluate the attenuation provided to employees using insert-type hearing-protective devices. There has, however, been little research into the validity of using standard audiometric headphones to determine attenuation values. The purpose of this study was to describe a procedure for determining the attenuation of insert-type hearing-protective devices using standard audiometric earphones, typical industrial audiometric 
equipment, and other easily obtainable materials.

Three different methods were used to evaluate the attenuation provided by an insert-type hearing-protective device, the E-A-R plug. The three methods used during this study were: (1) the use of one-third octave-band nolse stimuli in sound-field, in accord with the current aNsI standard; (2) the use of pure-tone stimuli presented under an earphone/support combination; and (3) the use of puretone stimuli presented under earphones-only. significant differences ( $p<.01$ ) were found between the sound-field and earphone/support methods at 3000 and $4000 \mathrm{~Hz}$. significant differences were found between the soundfield and earphonesonly methods at 2000 and $4000 \mathrm{~Hz}$. No signiflcant differences in attenuation values were found between the three test methods at $1000 \mathrm{~Hz}$.

The results of this study support the use, at selected frequencies, of both the earphone/support method and the earphones-only method for measuring the attenuation provided by expandable foam insert-type hearing protectors such as those used in this study. The use of these methods with other types of insert-type hearing protective devices will require further evaluation before any reliable field tests can be conducted.

\section{IMPL I CATIONS}

In general, the results of this study were encouraging regarding the use of standard audiometric earphones for 
measuring the attenuation provided by insert-type hearingprotective devices. However, the only type of earplug evaluated in this study was an expandable foam type plug. This type of plug, while extending from the ear canal, has no protruding tabs or handles which might easily be disturbed by the pressure of the earphone on the pinna. Therefore, the results of this study cannot be applied to other types of earplugs, including premolded, flanged, and custom molded earplugs. It is possible that significant differences might be found between "true" sound-field attenuation values and values obtained using the earphone/support method or the earphones-only method when evaluating other types of earplugs. It is especially likely that the earphones-only method may affect the attenuation values obtained from these types of earplugs due to the alteration of fit resulting from the earphones resting on the pinna and the earplug itself. Further testing should be directed at evaluating a variety of different plugs using the three methods presented in this study.

If further laboratory studies show good correlation between sound-field attenuation values and values obtained by the two alternate methods, then further field studies using these methods would be warranted. Such field studies, however, would raise additional questions which would need to be addressed. For example, which frequencies would be most appropriate for fleld testing and how would attenuation results vary with different types and configurations of 
hearing losses? Could the earphone/support method or the earphones only method be used to measure attenuation values for an employee who has a unilateral hearing loss, for example?

If these questions can be answered satisfactorily, then the "field" methods proposed in this study could be used by occupational hearing conservationists to more effectively meet the needs of employees involved in occupational hearing conservation programs. 


\section{BI BL I OGRAPHY}

ABEL, S.M., ALBERTI, P.W., and RIKO, K. (1982). User fitting of hearing protection: Attenuation results. In P.W. Albert l (Ed.), Personal hearing protection in industry. New York: Raven Press.

ANSI (1957). ANSI 224.22-1957. American national standard for the measurement of real-ear attenuation of ear protectors at threshold. New York: American National standards Institute.

ANSI (1974). ANSI S3.19-1974. American national standard method for the measurement of real-ear protection of hearing protectors and physical attenuation of ear muffs. New York: Amerlcan National standards Institute.

ANSI (1984). ANSI S12.6-1984. American national standard method for the measurement of the real-ear attenuation of hearing protectors. New York: Amer lcan National standards Institute.

BERGER, E. (1979). The threshold shift method of measuring hearing protector attenuation. $B$ A ROG1. Indianapolis, Indiana: E A R Division, Cabot Corporation.

BERGER, E. (1982). Laboratory estimate of the real world performance of hearing protectors. In P.H. Albert (Ed.) Personal hearing protection in industry (pp. 299-313). New York: Raven Press.

BERGER, E. (1984). Assessment of the performance of hearing protectors for hearing conservation purposes. Noise f vibration vontrol worldwide, 15(3), 75-81.

BERGER, E. (1986). Methods of measuring the attenuation of hearing protection devices. Journal of the acoustical soclety of america, 29(6), 1655-1687. 
CARHART, R., and JERGER, J.F. (1959). Preferred method for clinical determination of pure-tone thresholds. Journal of speech and hearing disorders, 24, 330-345.

EDWARDS, R.G., BRODERSON, A.B., GREEN, W.W., and LEMPERT, B.L. (1983). A second study of the effectiveness of earplugs as worn in the workplace. Nolse control engineering journal, 20(1), 6-15.

EDWARDS, R.G., HAUSER, W.P., MOISEBV, N.A., BRODERSON, A.B., and GREEN, W.W. (1978). Effectlveness of earplugs as worn in the workplace. Sound \& vibration. January 1978, 12-22.

FELDMAN, A. (1985). Federal regulations dealing with occupational nolse. In A.S. Feldman and C.T. Grimes (Eds.), Hearing conservation in industry. Baltimore: Williams and Wilkins.

GASAWAY, D.C. (1985). Hearing conservation: A practical manual and quide. Englewood cliffs: PrenticeHall, Inc.

HARVEY, D.G. (1981). A method to increase the effectiveness of ear protection. Sound and vibration. $15(5), 24-27$.

HUMES, L.E. (1983). A psychophysical evaluation of the dependence of hearing protector attenuation on nolse level. Journal of the acoust lcal society of America, 13(1), 297-311.

MARTIN, A. (1982). How realistic are standard subjective test methods for evaluating hearing protector attenuation? In P.W. Alberti (Ed.), Personal hearing protection in Industry, (pp. 273298). New York: Raven Press.

MELLNICK, W. (1985). Industrial Hearing Conservation. In J. Katz (Ed.), Handbook of clinical audiology. Baltimore: Willams and Wilkins.

MI CHAEL, R.I ., KERLIN, R.L ., BIENVENUE, G.R , PROUT, J.H., and SHAMPAN, J.I. (1976). A real ear fleld method for the measurement of the noise attenuation of insert-type hearling protectors. U.S. Dept. of HEW, Report No. 79-115, Cincinnati, Ohio.

NIXON, C.W. (1982). Hearing protection standards. In P.W. Albert1 (Ed.) Personal hearing protection in industry (pp. 69-90). New York: Raven Press. 
NORUSIS, M.J. (1983) . SPSSx: Introductory statistics quide. Chicago, Illinois: sPSS Inc.

Occupational Safety and Health Administration: Occupational noise exposure; hearing conservation amendment; final rules. Federal reaister, 48:46, March 8, 1983, 9776, Superintendent of Documents, Washington, D.C.

PADILLA, M. (1976). Ear plug performance in industrial field conditions. Sound \& vibration, 10(5), 33-36.

REGAN, D.E. (1975). Real ear attenuation of personal ear protective devices worn in industry. Doctoral thesis at Kent state University.

REGAN, D.E. (1977). Real ear attenuation of personal ear protective devices worn in industy. Audiology and hearing education, $\underline{3}(1), 16-17$.

RIKO, K., \& ALBERTI, P.W. (1983). Hearing protectors: A review of recent observations. Journal of occupational medicine, 25(7), 523-526.

ROYSTER, L.H. and ROYSTER, J.D. (1985). Hearing protection devices. In A.S. Feldman and C.T. Grimes (Eds.), Hearing conservation in industry. Baltimore: williams and Wilkins.

WAUGH, R. (1974). Pure-tone, third-octave, and octaveband attenuation of ear protectors. Journal of the acoustical society of America, 56(6), 1866-1869.

WEBSTER, J.C., THOMPSON, P.O., BEITSCHER, H.R. (1956). Noise bands versus pure-tone stimuli in measuring the acoustic attenuation of ear protective devices. Journal of the acoustical society of America, 28(4), 631-638. 


\title{
APPENDIX A
}

ANSI $\$ 12.6-1984$

\section{AMERICAN NATIONAL STANDARD Method for the Measurement of the Real-Ear Attenuation of Hearing Protectors}

\begin{abstract}
This standard specifies the laboratory psychophysical procedures and means of reporting results for measuring the noise-reducing capabilities of wearable devices that are used to protect the human auditory system against excessive sound. Procedures are performed by psychoacoustic test on human subjects and are designed to determine real-ear attenuation measured at hearing threshold. Although this standard yie:ds data that are collected at low sound levels, they are representative of the attenuation values of hearing protectors at elevated sound levels. The methodology is intended to yield optimum performance because it can be repeated consistently for reliable rank-ordering of protectors. The values will depict the noise-reducing capa-. bilities of hearing protectors only to the extent that users wear the devices in the same manner as did the test subjects. This standard does not address comfort and wearability features of hearing protectors. This standard is a revision of the real-ear measurement section of ANSI S3.19-1974, Measurement of Real-Far Protection of Hearing Protectors and Physical Attenuation of Ear Muffs. Physical measurement procedures are not contained in this document but will be considered as a separate standard. This document relates to International Standard ISO 4869-1981, AcousticsMeasurement of Sound Attenuation of Hearing Protectors-Subjective Method, 15 December 1981.
\end{abstract}




\section{CONTENTS}

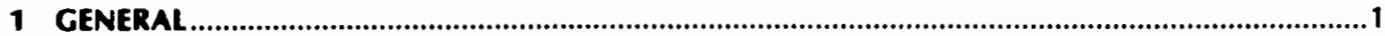

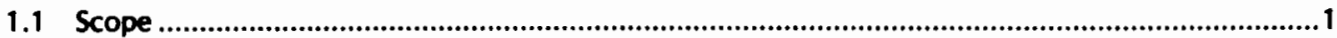

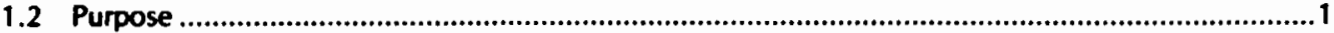

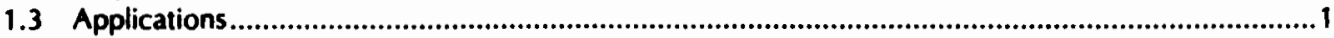

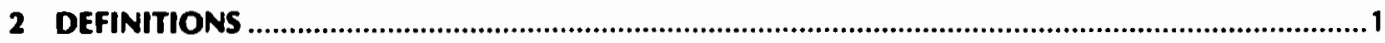

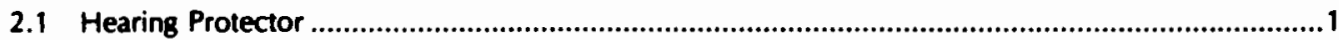

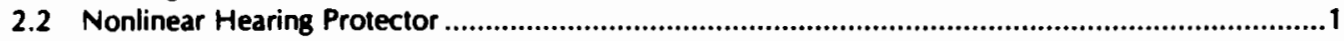

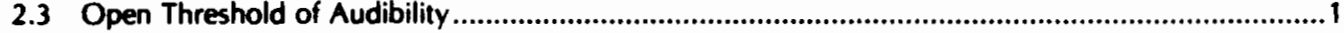

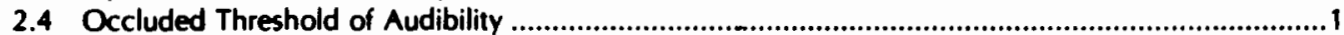

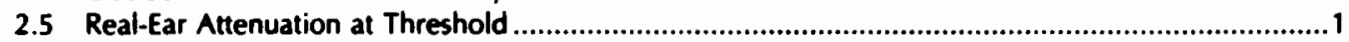

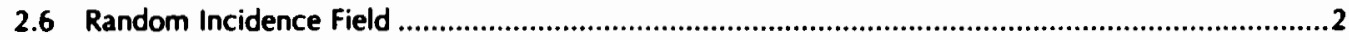

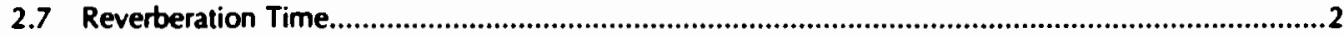

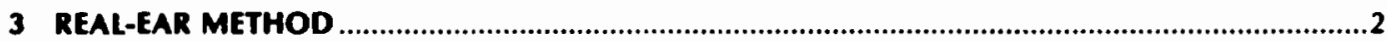

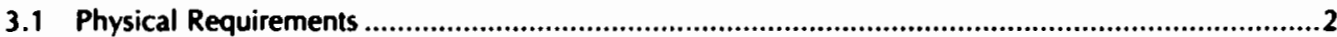

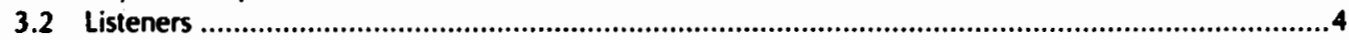

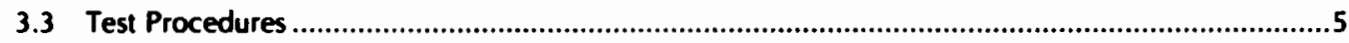

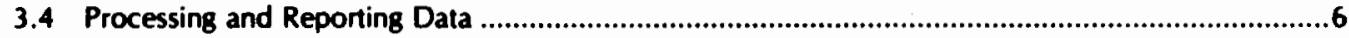

\section{FIGURES}

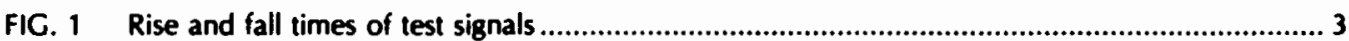

\section{TABLES}

TABLE I Maximum permissible ambient noise ....................................................................... 2

TABLE \|f Allowable random incidence field response variation...................................................... 3 


\section{American National Standard \\ Method for the Measurement of Real-Ear Attenuation of Hearing Protectors}

\section{GENERAL}

\subsection{Scope}

This standard specifies the laboratory psychophysical procedures and means of reporting results for measuring the noise reducing capabilities of wearable devices that are used to protect the human auditory system against excessive sound.

\subsection{Purpose}

The purpose of this standard is to describe procedures designed to determine real-ear attenuation measured by psychoacoustic tests at hearing threshold on human subjects.' The methodology is intended to yield optimum performance values which may not usually be obtained under field conditions. Optimum performance values have been chosen because they can be repeated consistently for reliable rank-ordering of protectors. The values will depict the noise-reducing capabilities of hearing protectors only to the extent that users wear the devices in the same manner as did the test subjects.

\subsection{Applications}

The method of this standard applies to conventional hearing protectors including communication units, special helmets, safety helmets, pressure suits and other systems with sound-attenuation features, and to hearing protective devices used in combination with one another, such as earplugs used in conjunction with earmuffs or helmets. The method may not be applicable for the evaluation of the performance of devices having nonlinear attenuation characteristics.

Athough the methodology of this document yields data that are collected at low sound levels (typically $10-60 \mathrm{~dB} r 20 \mu \mathrm{Pa}$ ), they are representative of the attenuation values of hearing protectors at elevated sound levels. Low-frequency results (below $500 \mathrm{~Hz}$ ) may be spuriouly high by a few decibel as a reult of mathing of the occluded ear threaholds cumed by physiological noine during the occhuded teet

\section{DEFINITIONS}

\subsection{Hearing Protector}

A device that is worn to reduce the harmful effects of sound on the auditory system.

2.1.1 Enplue $A$ hearing protector worn within the external ear canal (aural) or in the concha against the entrance to the external ear canal (semi-aura).

2.1.2 Earmuf. A hearing protector usually comprised of headband and earcups with a soft outer ring intended to fit snugly against the pinna (supra-aural) or the sides of the head around the pinna (circumaural).

2.1.3 Commmication beadeet. A device learplug or earmufi) designed primarily for communication which may also provide or be used for hearing protection.

2.1.4 Helmet. A device, sometimes functioning as a hearing protector, thet usually covers a substantial part of the head.

\subsection{Nonlinear Hearing Protector}

A device designed to provide hearing protection that changes as a function of sound level.

\subsection{Open Threshold of Audibility}

The minimum sound pressure level for a specified signal that is capable of evoking an auditory sensation when a hearing protector is not worn.

\subsection{Occluded Threshold of Audibility}

The minimum sound preasure level for a specified sigal that is capable of evoking an auditory sensation when the hearing protector under test is worn.

\subsection{Real-Ear Attenuation at Threshold}

The mean value (in decibels) of the occluded threahald of audibility minus the open threshold of audibility for all linteners on all trial under otherwiec identiol tent condition. 


\subsection{Random Incidence Field}

A sound field in which the angle of arrival of sound at a given point is random.

\subsection{Reverberation Time}

The time required for the mean-square sound pressure level, originally in a steady state, to fall $60 \mathrm{~dB}$ after the source is stopped.

\section{REAL-EAR METHOD}

\subsection{Physical Requirements}

\subsubsection{Acoustic Environment of Test Room}

\subsubsection{Ambient Noise}

The suitability of the ambient noise levels shall be verified using the following procedure.

(1) The ambient noise (with all signal presentation instrumentation on and no test signal present) as measured at the listener's head position in the room shall not exceed the octave band levels in Table I. The listener shall be abeent from the room during the messurement. All test signal gain controls shall be adjusted to $20 \mathrm{~dB}$ above the levels necessary to elicit open threshold of audibility at all test frequencies.

(2) When any extraneous noise becomes audible in the test room during testing, means shall be employed whereby the listener can signal the experimenter to stop the test. ${ }^{3}$

\subsubsection{Test Sounds}

Third-octave bands of noise shall be used as test sounds for measuring real-ear attenuation at threshold for at least the bands with the following center fre-

TABLE I. Maximum permissible ambient noise."

\begin{tabular}{cc}
\hline Frequecocy, Hz & Octave band, SPL \\
\hline 125 & 28 \\
250 & 18 \\
500 & 14 \\
1000 & 14 \\
2000 & 8 \\
1000 & 9 \\
2000 & 20
\end{tabular}

- Parmimible ambient noine levels are in decibels $r 20 \mu \mathrm{Pa}$ and are from now 1, Tals If, ANA s3.1-1977. quencies: $125,250,500,1000,2000,3150,4000,6300$, and $8000 \mathrm{~Hz}$. Test signals interrupted or pulsed a minimum of twice per second with a $50 \%$ duty cycle and without audible transients shall be used for the psychophysical procedures.

\subsubsection{Sound Field Characteristics}

An acceptable sound field shall be approximated by the following conditions.

(1) The sound shall be generated in a room whose reverberation time in the test space (without subject) shall not exceed 1.6 seconds for each of the test bands.

(2) The sound pressure level measured at six positions relative to the center of the subject's head (without subjects), $\pm 15 \mathrm{~cm}$ ( \pm 5.9 in.) in front-back, updown, and right-left dimensions, shall remain within a range of $6 \mathrm{~dB}$ for all test bands (see 3.1.1.2). The difference in sound pressure level between the right-left positions shall not exceed 2 dB.

(3) The directionality of the sound field shall be evaluated at the head center location for test bands with center frequencies greater than or equal to 500 Hz. The measurements shall be conducted with a directional microphone that exhibits at the one third-octave test bands at least $10 \mathrm{~dB}$ front-to-side rejection for a cosine microphone, or at least $10 \mathrm{~dB}$ front-to-back rejection for a cardioid microphone in its frec-field polar response. The cound field shall be considered to approximate a random incidence field if, when the microphone is rotated about the center of the test space through 360 degrees in each of the three perpendicular plenes of the room, the obeerved sound pressure level in each test band remains within the variation allowed in Table II. The sound pressure levels may also be obtained by measuring at fixed 15-degree increments as the microphone is rotated 360 degrees in each plane.

\subsubsection{Test Apparatus}

Test equipment shall include the following: noise generator, third-octave band filter set, control circuits, (on-of switch and calibrated attenuators), loudspeaker(s) with power amplifier, and a head-positioning device.

\subsubsection{Signal Source}

The signal source shall have uniform pink or white noise spectrum level. The test sounds shall be produced using a third-octave flter set whose band- 
TABLE II. Allowable random incidence feld response variation for corresponding microphone freeficld rejection."

\begin{tabular}{ll}
\hline Microphone free-field & $\begin{array}{c}\text { Allowable randon incidence } \\
\text { fejection, decibets }\end{array}$ \\
\hline 25 & 6 \\
20 & 5 \\
15 & 4 \\
10 & 3 \\
$<10$, microphone not tuitable & \\
\hline
\end{tabular}

- The variation in microphone response as the microphone is rotated in a random incidence field is related to the directional characteristics of the microphone and the degree of randomness of the field. Allowable wound feld response variations must be presented in terms of the free-field directional response characteristic of the microphone. Table II presents the free-field rejection values of directional microphones and corresponding allowable sound field variations for purposes of this standard. The microphone free-field rejection may be obtained by measurement or from the microphone manufacturer.

widths, band-edge frequencies, and other characteristics shall conform to the American National Standard Specifications for Octave, Half-Octave, and Third-Octave Band Filter Sets, S1.11-1966 (R1976), Class III. The mode of operation of the filters in changing from one contiguous band to another shall be a discrete step function; a gradual continuously adjustable mode of change is not acceptable.

\subsubsection{Control Circuits}

(1) Attenuators shall have a range of at least $90 \mathrm{~dB}$ for each test signal. The attenuator when connected in the system shail be calibrated at 2.5-dB steps or smaller. The measured difference in signal output between any two attenuator settings shall not differ from the indicated difference by more than threetenths $(0.3)$ of the indicated difierence measured in decibels or by $1.0 \mathrm{~dB}$, whichever is smaller. Corrections for departure from linearity shall be applied to the data when this requirement is not met.

(2) Automatic recording attenuator systems shall be provided with a switch for automatic pulsed presentation of the test signal. The pulsed sequence shall be generated in accordance with the following requirements (see Fig. 1):

(a) The rise time of the pulsed signal (from B to $C$ on Fig. 1) shall be at least $20 \mathrm{~ms}$ and shall not exceed 50 ms.

(b) The fall time of the pulsed signal (from $E$ to $G$ on Fig. 1) shall be at least $20 \mathrm{~ms}$ and shall not exceed $50 \mathrm{~ms}$.

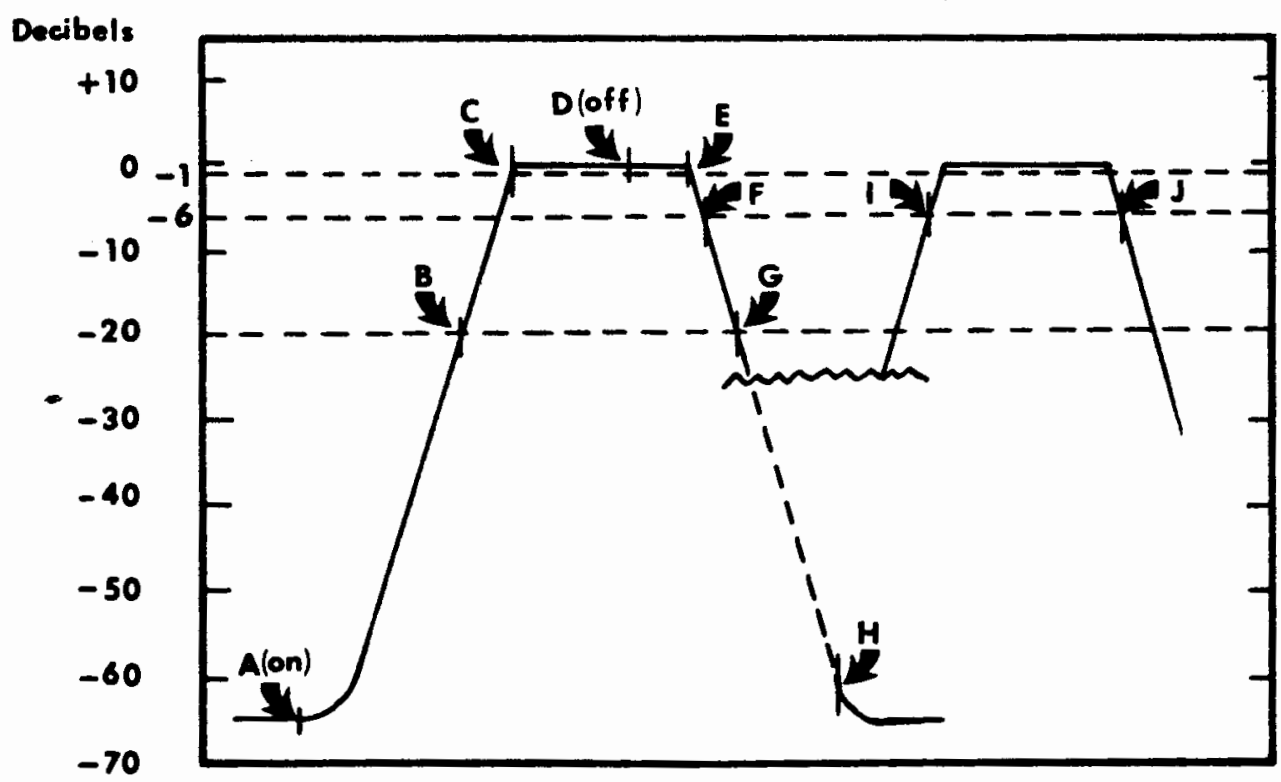

FIG. 1. Rise and fall times of test signals. 
(c) The sound pressure level shall vary smoothly and without discontinuities between $B$ and $C$ and between $\mathbf{E}$ and $\mathbf{G}$.

(d) The on-duration (from $\mathrm{C}$ to $\mathrm{E}$ on Fig. 1) shall be at least $150 \mathrm{~ms}$.

(c) The repetition rate (F to I and I to J) shall each have nominal values of $200 \mathrm{~ms}$."

(f) The signal level output in the OFF phase shall be at least $20 \mathrm{~dB}$ below the maximum level reached during the ON phase of each repeated pulse.

\subsubsection{Loudspeakers}

The loudspeaker(s) used in conjunction with the apparatus described in 3.1.2 shall provide a sound field such that at any test band the sound pressure level at the listener's position can be varied from at least $10 \mathrm{~dB}$ above the occluded threshold of hearing to $10 \mathrm{~dB}$ below the open threshold of hearing. For most protective devices this is equivalent to a level of $60 \mathrm{~dB}$ above to a level of $10 \mathrm{~dB}$ below the open threshold of audibility. ${ }^{5}$

\subsubsection{Head-Positioning Device}

Some means shall be used to provide a reference for maintaining the listener's head in a constant position (not a head rest; a plumb bob to the nose or the forehead of the listener has proven scceptable). This device shall not transmit to the listener's head any vibrations that might affect the measurements or present a reflective or absorptive surface that might alter the level of the sound at the ears of the subject.

\subsubsection{Distortion}

The entire system, up to the loudspeaker terminals, ahall produce less than $5 \%$ total harmonic distortion with the system set at maximum gain and the test signal being discrete pure tones corresponding to the center frequencies of the test bands. When the test room is excited by a third-octave band of noise at maximum gain, the cound pressure level measured at the head center location shall be at least $\mathbf{S} \mathrm{dB}$ down from the maximum level in adjacent third-octave binds and at least $30 \mathrm{~dB}$ down in third-octave bands one octave or more resooved from the center frequescy.

\subsubsection{Earmuff Device Force Measurement}

Some means shall be provided for the measurement of force exerted against the sides of the head by carmuff devices mounted on suspension systems. The measurements shall represent the force found in new, unused hearing protectors separated to a distance of $14.35 \mathrm{~cm}$ ( 5.65 in.) between earcups (median head width) and $13.08 \mathrm{~cm}$ (5.15 in.) between the inside of the headband and an imaginary line through the pivot points of the attachments of the headband to the earcups (mediam head height). These date shall be reported along with the real-ear attenuation data.

\subsection{Listeners}

3.2.1 Listeners to be used in the test described in the following section shall have hearing threshold levels that are no better than $-10 \mathrm{~dB}$ and no worse than 20 $\mathrm{dB}$ at all frequencies as measured by a standard audiometer (American National Standard S3.6-1969, Specifications for Audiometers).

3.2.2 No subject shall be used whose unoceluded thresholds (the average of three determinations) in the test room are better than $8 \mathrm{~dB}$ below the ambient noise levels measured in the test room at the seven octave bands centered on the test frequencies from 125 to $8000 \mathrm{~Hz}$

3.2.2. An exception to this requirement is based on the lowest unoceluded hearing threshold levels at each test frequency of all prior subjects measured in the test facility. Listeners whose unoccluded bearing thresholds (average of three determinations) are $3 \mathbf{d B}$ or more above the minimum threahold previously measured at each frequency under the sume ambient noise conditions may also be used as subjects."

32.3 The variability of the open threshold of audibility of listeners selected as subjects for these tests shall be, on three successive open threshold measurements, no greater than $\mathbf{S} \mathbf{d B}$ at all test frequencies, as measured in the sound field.

3.2.4 Listeners who satisfy the other requirements of this standard and who do obtain a good fit with the test item (3.3.3.1) shall not be dismissed for reporting small amounts of attenuntion. In reporting the results, listeners for whom a good fit cannot be obtained shall be noud, bet should not be included in the eveluntion. 


\subsection{Test Procedures}

\subsubsection{Psychophysical Procedures}

3.3.1.I Listeners shall be completely informed regarding the test situation and procedure.

3.3.1.2 The listener shall be seated in such a way that, using the head-positioning reference device, the listener's head will be pleced in the same "fixed" position in the sound field for all repeated measurements.

3.3.1.3 The methods to be used in measuring the open and occluded thresholds of audibility shall be identical, and shall include any recognized psychophysical method or variants thereof capable of producing the data required in Sec. 3.4. The procedure used shall be reported in sufficient detail that it may be reproduced by any facility otherwise qualified under this standard.

\subsubsection{Automatic Recording Audiometer}

The audiogram produced by an automatic recording audiometer shall be scored as follows:

(1) A trace is considered of doubtful reliability and shall be repeated if, ignoring the first reversal following a change of frequency and occasional reversals associated with trace excursions of $3 \mathrm{~dB}$ or less;

(a) There are less than six (6) reversals.

(b) Any peak is lower than any valley.

(c) The range of excursions (any peak to valley difference) exceeds $20 \mathrm{~dB}$.

(2) Acceptable traces shall be scored by ignoring the first reversal following a change of frequency and then averaging together an equal number of peaks and valleys of the tracing at a given frequency.

(3) The average value shall be rounded to the nearest whole number in decibels.

(4) When the trace excursions meet the sbove criteria, very similar results may be obtained more simply by "visual averaging," in which a horizontal line drawn through the center of the tracing is used to estimate the average value.

\subsubsection{Open Threshold of Audibility}

3.3.2.I In order to allow for accommodation to the test situation, listeners shall be seated in the test room, with no signals present, for a minimum period of 5 minutes prior to the initial trid of a test session, after which time the threshold determination may begin.
3.3.2.2 An open threshold of audibility for all test bands shall be measured immediately before or after each set of occluded thresholds, the order to be alternated. This procedure provides three sets of open ear and three sets of occluded ear data for each subject. The same procedure shall be used for measuring the open and the occluded thresholds of audibility.

\subsubsection{Occluded Threshold of Audibility}

\subsubsection{Fitting Hearing Proteclors}

The acoustic fit of hearing protective devices is critical to the amount of attenuation obtained. The method of installation for occluded threshold determinations shall be experimenter supervised fit since this standard is intended to yield the optimum performance values of tested hearing protectors. Eyeglasses shall not be worn during earmuff evaluations. The reduction in attenuation of muff type hearing protectors worn over eyeglasses is discussed in the reference in Footnote 7.

\subsubsection{Experimenter Supervised Fit}

The experimenter shall give each listener procise instructions and practice on fitting the hearing protec. tors, in accordance with instructions from the manufacturer, and shall select the proper size hearing protector for the listener. Earplugs shall be inserted and carmuffs shall be put on by the listener in the test chamber. After the hearing protector has been installed, noise shall be introduced whose overall sound pressure level at the listener's position is 60 to $70 \mathrm{~dB}$ with reference to $20 \mu \mathrm{Pa}$. The listener shall be instructed to manipulate the hearing protector until satisfied that the noise is minimal. The experimenter shall personally check each hearing protector installation to assure a good fit and acoustic seal. When the experimenter deems it necessary, the subject shall be required to reinsert earplugs and readjust other protectors in accordance with the manufacturer's instructions as many times as necessary to obtain a "best" fit prior to testing but not after the test has begun. Further manipulation of the hearing protectors to im. prove hearing protection after the acquisition of audiometric data is begun shall be prohibited.

\subsubsection{Occluded Threshold Levels}

After the hearing protector has been installed in accordance with 3.3.3.1 and 3.3.3.2, a threshold of audibility for the test sigmals shail be measured in exactly the same way as prescribed for the open thresholds (3.3.2) These level shill be the occluded threahold. 


\subsubsection{Number of Hearing Protector Units}

A minimum of two units of a hearing protector model shall be used in a test. The units shall be distributed among the subjects in such a way as to achieve proportional representation of the units in the measurements. An individual subject shall wear the same protector for the entire test.

\subsubsection{Minimum Samples}

The attenuation at threshold for each listener shall be based, for each test signal, on measures of open thresholds made on no less than three separate trials and on measures of accluded thresholds made on no less than three separate trials. Each separate trial shall include a refit of the hearing protector. Frequent rest periods shall be provided the subject during the threshold determinations. Measurements shall be made on not less than ten subjects.

\subsection{Processing and Reporting Data}

\subsubsection{Recording Data}

The data to be recorded, from which the hearing protector attenuation values will be calculated, shall consist of three open and three occluded threshold levels at each test frequency for each test subject. The threshold values need not be absolute sound pressure levels and may only be relative pressure levels, since the calculated attenuation is the difference in decibels between pairs of open and occluded measurements.

\subsubsection{Measurements to be Reported}

The measurements shall be summarized for at least each of the nine specified third-octave band test signals in terms of a mean and a standard deviation. The mean attenuation shall be computed at each frequency by averaging the calculated attenuation values (from Sec. 3.4.1) across all subjects. The standard deviations shall be computed using the formula

$$
\sigma=\sqrt{\frac{\Sigma d^{2}}{N-1}},
$$

where $d$ is the difference between the grand mean and an individual observation and $N$ is the number of observations (typically 30,10 subjects with three measures each). There will be as many attenuation values and standard deviations as there are test signals. The data shall be summarized in a table or graph that displays real-ear attenuation at threshold and the associated standard deviation, $a$ a function of the frequency of the third-octave teat bends of noise.
3.4.2.1 When attenuation data are presented in graphic form, a paper shall be used whose frequency scale along the abscissa is in equal intervals of third-octave band center frequencies and whose attenuation along the ordinate is linear in decibels. The length for a decade of third-octaves shall be equal to the length for 25 dB.

3.4.2.2 Listeners shall be described in terms of age, sex, and manner of selection, including discussion of any subjects who were dismissed because an adequate fit could not be obtained.

3.4.2.3 The earmuff force measurements shall be described and noted on the graphic or tabular displays (or both) of the attenuation data.

\section{FOOTNOTES}

'Procedures described in the Phyical Ineertion Loss Method (supplemental to this standard) are performed by physical test on a dummy bead and are designed to messure insertion loss at relatively high sound presure levels. The test is intended to supplement the realear attenution teat.

${ }^{2} A$ real-head insertion loss method (mesurements made with a miniature microphone positioned under an earcup worn by a buman subject), as bes sometime been applied in research and development work, is not standardized in this document. Data and experience with this method have been exumined and found to be insulacient for development of a uniform procedure suitable for andardization at this time.

'Any audible noive in the test room may be distracting or may caun making over a portion of the renge of teat signals. This will elevate the open threbold of audibility and realt in erroneoully anall valves of realear attenution for the device under test. Many roows that cannot meat the limiting anbient noise requirements continoouly will be suitable if ten periads are selected during times of minimum (acceptable) noise.

The preferred repetition rate is 2.5 per sound. The intervals $F I$ and IJ are, however, given as nominal values without tolerances recosniring that lower repetition rates, typically 2 per second, are provided on many existing audiometers.

The level of $10 \mathrm{~dB}$ below the threshold of audibility may be calculated on the besis of electrical calibration.

The limitations on unoceluded threhold relative to the ambient noise levels in the teat enviromment are intended to minimize the potential for the elevation of the unoceluded threahold due to muaking eifects. If sucb a malkins efect occurs it would tend to decreace the mean attenuation and possibly increase the standard deviationa. The finitation is bad on making studies in which a narrow band

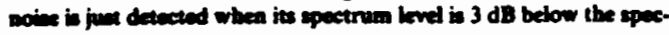


ANSI S12.6-1984

tnum level of the wide band master. An additional $5 \mathrm{~dB}$ is allowed to translate to third-octave band signal levels and full octave bend embient noise (masker) levels. This information is documented in the following report: P.M. Schacknow and D. H. Ratb, "Noise-Intensity Discrimination: Effects of Bandwidth Conditions and Mode of Masker Presentation." J. Acoust. Soc. Am. 60. 893-905 (1976).
The effects of wearing eyeglasses on earmuff attenuation are dis. cussed in "Hearing Protection of Earmuffs Worn Over Eyeglesses," Aerospace Medical Research Laboratory, Technical Report 74-61, AD785386, which may be obtained from National Technical Information Service (NTIS), 5285 Port Royal Road, Springfield, Virginia 22151. 


\section{APPENDIX B}

INSTRUCTIONS FOR INSERTING THE E-A-R PLUG

The Cabot Corporation, manufacturer of the E-A-R Plug, provides the following insertion instructions on each package of their earplugs:

1. With clean hands slowly roll and compress plug into a very thin, crease-free cylinder.

2. While compressed, insert Plug well into ear canal. Fitting is easier if outer ear is pulled outwards and upwards during insertion.

3. With fingertip, hold plug in place until it begins to expand and block noise. 


\section{APRENDIX C \\ THRESHOLD LEVELS* OBTAINED USING STANDARD \\ AND ALTERNATE TEST METHODS}

Subject 1

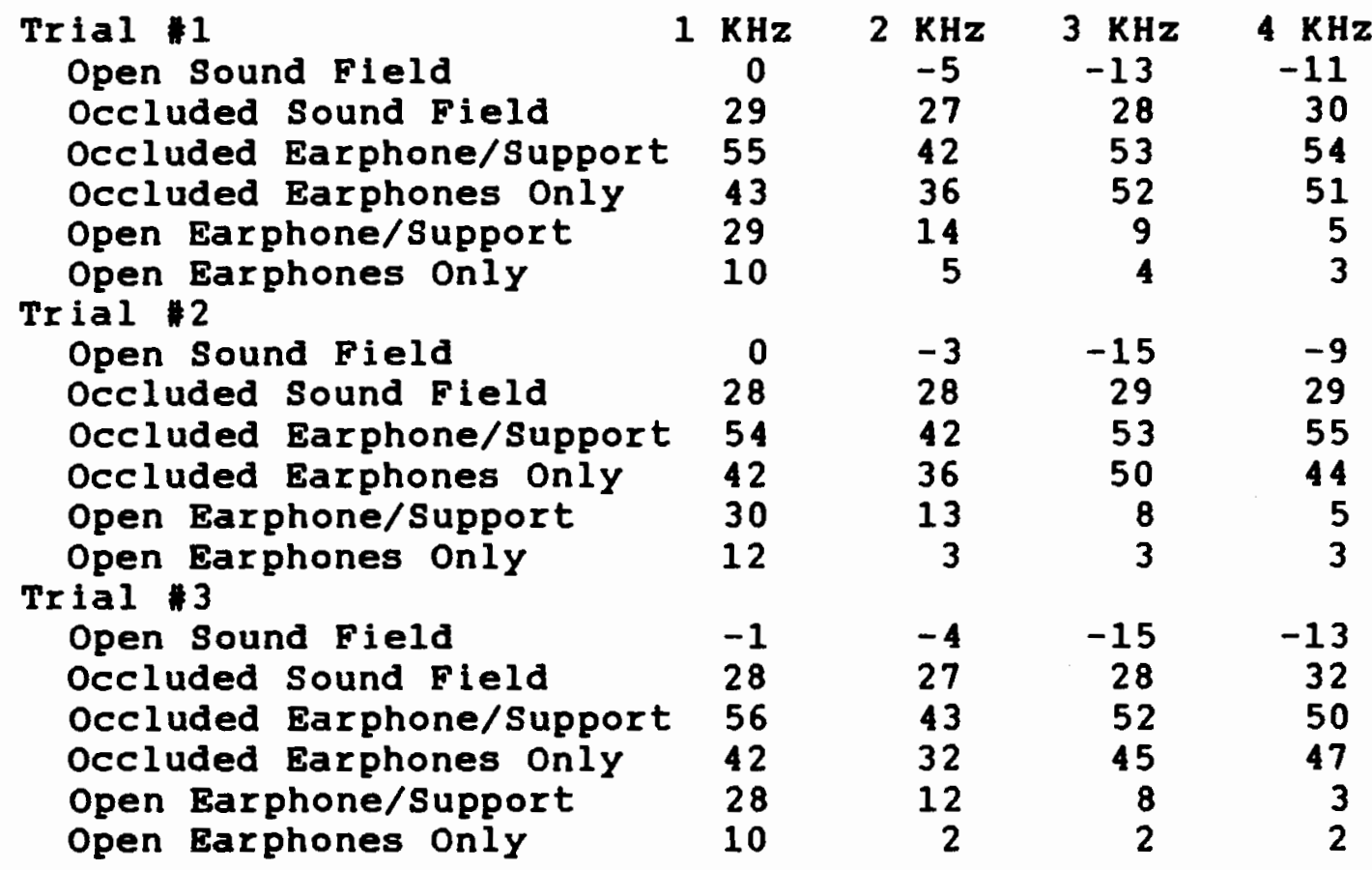

* Threshold levels are expressed in dB HI, as measured on the audiometer attenuator dial. 
subject 2

\begin{tabular}{|c|c|c|c|c|}
\hline Trial $\# 1$ & $1 \mathrm{KHz}$ & $2 \mathrm{KHz}$ & $3 \mathrm{KHz}$ & $4 \mathrm{KHz}$ \\
\hline $\begin{array}{l}\text { Open Sound Field } \\
\text { occluded Sound Field }\end{array}$ & $\begin{array}{r}-15 \\
15\end{array}$ & $\begin{array}{r}-14 \\
19\end{array}$ & $\begin{array}{r}-20 \\
21\end{array}$ & $\begin{array}{r}-15 \\
27\end{array}$ \\
\hline Occluded Earphone/Support & 21 & 27 & 37 & 41 \\
\hline Occluded Earphones Only & 27 & 32 & 43 & 39 \\
\hline Open Earphone/support & -5 & -6 & -9 & -1 \\
\hline $\begin{array}{l}\text { Open Earphones Only } \\
\text { Trial } 2\end{array}$ & 3 & -6 & -6 & -9 \\
\hline Open Sound Field & -15 & -12 & -18 & -15 \\
\hline Occluded Sound Field & 15 & 20 & 18 & 23 \\
\hline Occluded Earphone/Support & 33 & 30 & 35 & 38 \\
\hline Occluded Earphones Oniy & 24 & 24 & 34 & 30 \\
\hline Open Earphone/Support & 5 & 0 & -7 & -3 \\
\hline $\begin{array}{l}\text { Open Earphones only } \\
\text { Trial } 3\end{array}$ & 0 & -7 & -9 & -9 \\
\hline Open sound Field & -12 & -10 & -16 & -15 \\
\hline Occluded Sound Field & 12 & 19 & 15 & 20 \\
\hline Occluded Earphone/Support & 34 & 30 & 40 & 39 \\
\hline Occluded Earphones Onìy & 27 & 24 & 32 & 32 \\
\hline Open Earphone/Support & 4 & $\begin{array}{r}2 \\
-6\end{array}$ & 2 & 2 \\
\hline Open Earphones Only & 0 & -6 & -3 & -4 \\
\hline
\end{tabular}

Subject 3

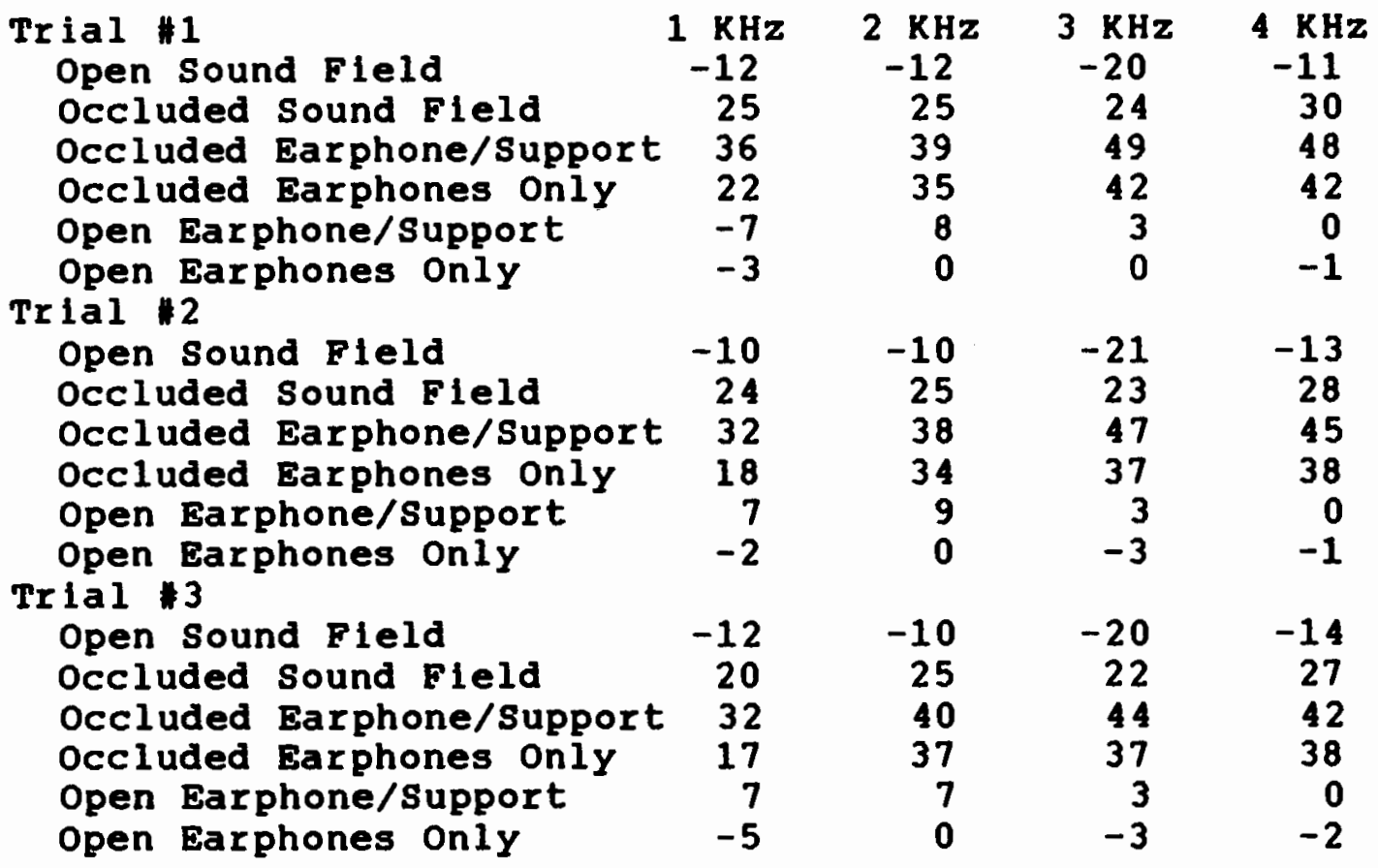


Subject 4

\begin{tabular}{|c|c|c|c|c|}
\hline Trial 1 & & & & \\
\hline $\begin{array}{l}\text { Trial } 1 \\
\text { Open Sound Field }\end{array}$ & $1 \mathrm{KHz}$ & $2 \mathrm{KHz}$ & $3 \mathrm{KHz}$ & $4 \mathrm{KHz}$ \\
\hline $\begin{array}{l}\text { Open Sound Field } \\
\text { occluded Sound Field }\end{array}$ & -15 & -19 & -20 & -17 \\
\hline Occluded Earphone/Support & $\begin{array}{l}21 \\
39\end{array}$ & $\begin{array}{l}18 \\
42\end{array}$ & $\begin{array}{l}16 \\
42\end{array}$ & $\begin{array}{l}24 \\
42\end{array}$ \\
\hline Occluded Earphones oniy & 35 & 34 & 34 & 33 \\
\hline Open Earphone/support & 3 & 4 & 4 & 0 \\
\hline Open Earphones only & -10 & -8 & -1 & -6 \\
\hline Trial 2 & & & & \\
\hline Open Sound Field & -12 & -16 & -22 & -16 \\
\hline Occluded Sound Field & 28 & 20 & 24 & 24 \\
\hline Occluded Earphone/Support & 42 & 44 & 48 & 47 \\
\hline Occluded Earphones Oniy & 32 & 37 & 37 & 38 \\
\hline Open Earphone/Support & 6 & 10 & 5 & 4 \\
\hline Open Earphones oniy & -6 & -3 & 2 & -3 \\
\hline Trial $\# 3$ & & & & \\
\hline Open Sound Field & -8 & -7 & -18 & -14 \\
\hline Occluded Sound Field & 32 & 30 & 23 & 27 \\
\hline Occluded Earphone/Support & 43 & 48 & 48 & 47 \\
\hline cluded Earphones only & 39 & 42 & 39 & 35 \\
\hline Open Earphone/support & 6 & 10 & 4 & 3 \\
\hline Open Earphones Oniy & -7 & -5 & -1 & -2 \\
\hline
\end{tabular}

Subject $\$ 5$

$\begin{array}{lcccc}\text { Trial 1 } & 1 \mathrm{KHz} & 2 \mathrm{KHz} & 3 \mathrm{KHz} & 4 \mathrm{KHz} \\ \text { Open Sound Field } & -8 & -8 & -23 & -22 \\ \text { Occluded Sound Field } & 22 & 23 & 25 & 22 \\ \text { Occluded Earphone/Support } & 42 & 39 & 42 & 45 \\ \text { Occluded Earphones On1Y } & 22 & 32 & 37 & 42 \\ \text { Open Earphone/Support } & 6 & 8 & -3 & -3 \\ \text { Open Earphones Only } & -3 & -3 & -8 & -7 \\ \text { Trial } & & & & \\ \text { Open Sound Field } & -5 & -8 & -18 & -18 \\ \text { Occluded Sound Field } & 27 & 27 & 29 & 29 \\ \text { Occluded Earphone/Support } & 43 & 47 & 47 & 48 \\ \text { Occluded Earphones On1Y } & 32 & 37 & 37 & 42 \\ \text { Open Earphone/Support } & 10 & 9 & -2 & -2 \\ \text { Open Earphones Only } & -1 & -2 & -8 & -8 \\ \text { Trial 3 } & & & & \\ \text { Open Sound Field } & -6 & -6 & -20 & -18 \\ \text { Occluded Sound Field } & 23 & 27 & 21 & 23 \\ \text { Occluded Earphone/Support } & 38 & 42 & 46 & 49 \\ \text { Occluded Earphones Only } & 32 & 40 & 39 & 42 \\ \text { Open Earphone/Support } & 10 & 9 & -1 & -3 \\ \text { Open Earphones Only } & -8 & -3 & -5 & -4\end{array}$


Subject $\$ 6$

Trial 1

Open Sound Field

$1 \mathrm{KHz}$

$-10$

$2 \mathrm{KHz}$

$3 \mathrm{KHz}$

$4 \mathrm{KHz}$

occluded sound Field

22

Occluded Earphone/Support 37

37

Occluded Earphones only

4

Open Earphone/Support

2

-13
22

$-23$

$-22$

open Earphones OnIy

37

17

19

33

42

48

2

48

53

$-3$

$\begin{array}{rr}0 & -3 \\ -8 & -5\end{array}$

Trial $: 2$

Open sound Field

$-10$

$-15$

occluded sound Field

24

Occluded Earphone/support

37

occluded Earphones only

30

Open Earphone/Support

5

Open Earphones only

0

22

34

30

Trial 3

Open Sound Field

$-11$

18

occluded sound Field

34

Occluded Earphone/support

32

Occluded Earphones only

7

open Earphones only

5

3

$-3$

$-20$

$-18$

22

25

44

50

39

47

$-3$

$-5 \quad-4$

$-15$

$-23$

$-15$

22

20

22

34

42

47

32

40

47

3

$-7$

3

4

$-8-10$

subject $\$ 7$

\section{Trial 1}

Open sound Field

occluded sound Fleld

Occluded Earphone/Support

occluded Earphones only

Open Earphone/support

Open Earphones on $1 y$

Trial 2

Open sound Field

occluded sound Fleld

Occluded Earphone/support

occluded Earphones only

Open Earphone/support

Open Earphones only

Trial 3

Open sound Field

occluded sound Field

occluded Earphone/support

occluded Earphones only

Open Earphone/support

Open Earphones only
$1 \mathrm{KHz}$

$-8$

22

37

24

8

$-3$

$-6$

25

47

34

10

$-3$

$-8$

24

40

27

12

$-5$
$2 \mathrm{KHz}$

$-8$

27

39

33

13

4

$-6$

28

44

37

14

2

$-8$

25

43

37

15

3
$3 \mathrm{KHz}$

$$
-16
$$

24

57

39

10

3

$-16$

27

54

43

10

6

$-13$

25

52

39

9

3
$4 \mathrm{KHz}$

$-13$

32

52

42

9

5

$-12$

37

55

47

6

4

$-11$

29

52

49 
Subject 8

$\begin{array}{lccrr}\text { Trial 1 } & 1 \mathrm{KHZ} & 2 \mathrm{KHZ} & 3 \mathrm{KHz} & 4 \mathrm{KHz} \\ \text { Open Sound Field } & -14 & -6 & -14 & -13 \\ \text { Occluded Sound Field } & 22 & 25 & 28 & 29 \\ \text { Occluded Earphone/Support } & 42 & 44 & 50 & 55 \\ \text { Occluded Earphones OnIy } & 29 & 37 & 40 & 49 \\ \text { Open Earphone/Support } & 7 & 8 & 2 & 8 \\ \text { Open Earphones Only } & 2 & -3 & -3 & 2 \\ \text { Trial 2 } & -16 & -6 & -17 & -11 \\ \text { Open Sound Field } & 17 & 23 & 30 & 33 \\ \text { Occluded Sound Field } & 32 & 44 & 47 & 54 \\ \text { Occluded Earphone/Support } & 32 & 40 & 44 & 50 \\ \text { Occluded Earphones On1Y } & 27 & 12 & 3 & 3 \\ \text { Open Earphone/Support } & 2 & 1 & -3 & 2 \\ \text { Open Earphones Only } & -3 & & & \\ \text { Trial 3 } & & -8 & -17 & -11 \\ \text { Open Sound Field } & -11 & 22 & 26 & 34 \\ \text { Occluded Sound Field } & 20 & 39 & 53 \\ \text { Occluded Earphone/Support } & 30 & 39 & 44 & 46 \\ \text { Occluded Earphones Only } & 28 & 37 & 42 & 7 \\ \text { Open Earphone/Support } & 0 & 10 & 1 & 1 \\ \text { Open Earphones Only } & -2 & 2 & 2 & \end{array}$

\section{Subject 9}

Trial 1

Open Sound Field

occluded sound Field

Occluded Earphone/Support

occluded Earphones only

Open Earphone/Support

Open Earphones Only

Trial 2

Open Sound Field

occluded Sound Field

occluded Earphone/Support

occluded Earphones only

Open Earphone/Support

Open Earphones only

Trial 3

open Sound Field -11

occluded Sound Field

occluded Earphone/Support

Occluded Earphones only

Open Earphone/support

Open Earphones Only

$\begin{array}{cccc}1 \mathrm{KHz} & 2 \mathrm{KHz} & 3 \mathrm{KHz} & 4 \mathrm{KHz} \\ -16 & -11 & -15 & -15 \\ 20 & 22 & 20 & 24 \\ 44 & 40 & 40 & 44 \\ 25 & 30 & 27 & 45 \\ 12 & 1 & -3 & 8 \\ -5 & -10 & -10 & -1 \\ & & & \\ -11 & -12 & -14 & -12 \\ 22 & 27 & 22 & 25 \\ 49 & 40 & 42 & 42 \\ 36 & 32 & 33 & 40 \\ 13 & 4 & 0 & 9 \\ -3 & -8 & -8 & -1\end{array}$

$\begin{array}{rrrr}-11 & -10 & -15 & -13 \\ 20 & 25 & 22 & 22 \\ 44 & 39 & 40 & 44 \\ 37 & 30 & 35 & 48 \\ 14 & 4 & -3 & 4 \\ -5 & -10 & -10 & 0\end{array}$ 
subject 10

Trial 1

Open Sound Field

occluded Sound Field

Occluded Earphone/support

occluded Earphones only

Open Earphone/support

Open Earphones only

Trlal 2

Open Sound Field

Occluded sound Fleld

Occluded Barphone/support

Occluded Earphones oniy

Open Earphone/Support

open Earphones only

Trial \#3

Open Sound Field

occluded Sound Fleld

occluded Earphone/support

Occluded Earphones only

Open Earphone/support

Open Earphones Only
$1 \mathrm{KHz}$

$-14$

17

40

27

9

$-3$

$$
-13
$$

22

44

30

10

$-3$

$-13$

17

46

32

9

$-3$
$2 \mathrm{KHz}$

$-11$

22

42

32

8

$-3$

$-13$

25

42

37

7

$-2$

$-11$

20

42

34

7

$-5$
$3 \mathrm{KHz}$

$-13$

24

50

35

2

$-2$

$-16$

22

50

40

2

$-1$

-17
28

49

41

1

$-2$

$-5$
$-15$

$4 \mathrm{KHz}$

$-13$

27

47

38

2

$-3$

$-13$

32

49

40

2

$-3$

28

52

42

1 
APPENDIX D

AVERAGED ATTENUATION RESULTS FOR INDIVIDUAL SUBJECTS

subject 1

Sound-Field

Earphone/Support

Earphones on 1 y

Subject \#2

Sound-Field

Earphone/Support

Earphones oniy

Subject $\$ 3$

Sound-Field

Earphone/Support

Earphones only

Subject 4

Sound-Field

Earphone/Support

Earphones only

Subject $\$ 5$

Sound-Field

Earphone/Support

Earphones only

Subject $\# 6$

Sound-Field

Earphone/Support

Earphones Only
$1000 \mathrm{~Hz} 2000 \mathrm{~Hz} \quad 3000 \mathrm{~Hz} \quad 4000 \mathrm{~Hz}$

$\begin{array}{llll}28.67 & 31.33 & 42.67 & 41.33 \\ 26.00 & 29.00 & 44.33 & 48.67 \\ 31.67 & 31.33 & 46.00 & 44.67\end{array}$

$1000 \mathrm{~Hz} 2000 \mathrm{~Hz} 3000 \mathrm{~Hz} 4000 \mathrm{~Hz}$

$\begin{array}{llll}28.00 & 31.33 & 36.00 & 38.33 \\ 28.00 & 30.33 & 42.00 & 40.00 \\ 25.00 & 33.00 & 42.33 & 41.00\end{array}$

$1000 \mathrm{~Hz} 2000 \mathrm{~Hz} 3000 \mathrm{~Hz} 4000 \mathrm{~Hz}$
34.33

26.33

22.33
36.00

31.00

35.33
43.33

43.67

40.67
41.00

45.00

40.67
$1000 \mathrm{~Hz} 2000 \mathrm{~Hz} 3000 \mathrm{~Hz} 4000 \mathrm{~Hz}$

$\begin{array}{llll}38.67 & 36.67 & 41.00 & 41.00 \\ 36.33 & 36.67 & 41.67 & 43.00 \\ 43.00 & 43.00 & 36.67 & 39.00\end{array}$

$1000 \mathrm{~Hz} 2000 \mathrm{~Hz} 3000 \mathrm{~Hz} 4000 \mathrm{~Hz}$

$\begin{array}{llll}30.33 & 33.00 & 45.33 & 44.00 \\ 32.33 & 34.00 & 47.00 & 50.00 \\ 33.33 & 39.00 & 44.67 & 48.33\end{array}$

$1000 \mathrm{~Hz} 2000 \mathrm{~Hz} 3000 \mathrm{~Hz} 4000 \mathrm{~Hz}$

$\begin{array}{llll}31.67 & 36.33 & 41.67 & 40.33 \\ 30.67 & 32.33 & 40.67 & 49.00 \\ 29.00 & 36.00 & 44.00 & 52.00\end{array}$


subject 7

Sound-Field

Earphone/Support

Earphones only

subject 8

Sound-Field

Earphone/support

Barphones Only

subject 9

Sound-Field

Earphone/support

Earphones only

Subject $\$ 10$

Sound-Field

Earphone/support

Barphones only
31.33

31.33

32.00

34.00

28.00

40.33

44.67

36.33

44.67

45.00

41.67

$1000 \mathrm{~Hz} 2000 \mathrm{~Hz} 3000 \mathrm{~Hz} 4000 \mathrm{~Hz}$

$\begin{array}{llll}33.33 & 30.00 & 44.00 & 43.67 \\ 31.67 & 32.33 & 45.00 & 48.00 \\ 29.00 & 38.00 & 41.33 & 46.67\end{array}$

$1000 \mathrm{~Hz} 2000 \mathrm{~Hz} \quad 3000 \mathrm{~Hz} \quad 4000 \mathrm{~Hz}$

$\begin{array}{llll}33.33 & 35.67 & 36.00 & 37.00 \\ 32.67 & 36.67 & 42.67 & 36.33 \\ 37.00 & 40.00 & 41.00 & 45.00\end{array}$

$1000 \mathrm{~Hz} 2000 \mathrm{~Hz} 3000 \mathrm{~Hz} \quad 4000 \mathrm{~Hz}$

$\begin{array}{llll}32.00 & 34.00 & 40.00 & 42.67 \\ 34.00 & 34.67 & 48.00 & 47.67 \\ 32.67 & 37.67 & 39.67 & 43.67\end{array}$

